Article

\title{
Trends in Excess Winter Mortality (EWM) From 1900/01 to 2019/20-Evidence for a Complex System of Multiple Long- Term Trends
}

\author{
Rodney P Jones ${ }^{1, *}$, and Andriy Ponomarenco ${ }^{2}$ \\ 1 Healthcare Analysis \& Forecasting; hcaf_rod@yahoo.co.uk \\ 2 Odessa Medical University; andrij.ponomarenko@onmedu.edu.ua \\ * Correspondence: hcaf_rod@yahoo.co.uk
}

\begin{abstract}
Trends in excess winter mortality (EWM) were investigated from the winter of 1900/01 to 2019/20. During the 1918-1919 Spanish flu epidemic a maximum EWM of 100\% was observed in both Denmark and the USA. During the Spanish flu epidemic in the USA 70\% of excess winter deaths were coded to influenza. EWM steadily declined from the Spanish flu peak to a minimum around the 1960's to 1980 's. There is evidence that this decline was accompanied by a shift in deaths away from the winter, and that the EWM calculation shifted from a maximum around April to June in the early 1900's to around March since 1967. EWM has a good correlation with the number of estimated influenza deaths, but in this context influenza pandemics after the Spanish flu only had an EWM equivalent to that for seasonal influenza. Using data from 1980 onward the effect of influenza vaccination on EWM was examined using a large international data set. No effect of increasing influenza vaccination could be discerned; however, there are multiple competing forces influencing EWM which will obscure any underlying trend, e.g, increasing age at death, multimorbidity, dementia, polypharmacy, diabetes, and obesity - all of which either interfere with vaccine effectiveness or are risk factors for influenza death. After adjusting the trend in EWM in the USA, influenza vaccination can be seen to be masking higher winter deaths among a high morbidity US population. Winter deaths are clearly the outcome of a very complex biological system of competing long-term trends.
\end{abstract}

Keywords: winter mortality; trends; season; estimated influenza mortality; pandemic influenza; aging

\section{Definitions}

Total winter deaths $(\mathrm{TWD})=$ total deaths during the 4 winter months, December to March. This total is calculated as a rolling total to detect winter deaths in the Southern hemisphere, near the equator and in those years when influenza outbreaks occur earlier or later than December/March.

Excess winter deaths $(E W D)=$ total deaths during the 4 winter months minus half the deaths in the 8 non-winter months. As a rolling calculation.

Excess winter mortality $(\mathrm{EWM})=$ total deaths during the 4 winter months divided by half the total deaths during the 8 non-winter months. As a rolling calculation.

Both TWD and EWD need to be adjusted for growth in deaths over time. EWM does not need such an adjustment. For example, between Jan-07 and Dec-19 deaths in the USA grew by $0.14 \%$ per month which makes a negligible impact on the EWM calculation. 


\section{Introduction}

A previous study in IJERPH investigated the use of excess winter mortality (EWM) as a forensic tool [1]. The magnitude of EWM was shown to be greatly influenced by respiratory deaths and by a mix of other factors such as access to health care, relative wealth, home insulation (indoor temperature), and age at death [1,2]. All these factors are changing over time. Can EWM shed light upon other issues?

There has been considerable debate around exactly how many influenza deaths have occurred during various pandemics. The difficulty is that such deaths must be estimated and that different estimation methods give widely different answers [3-9]. Deaths due to influenza are a subset of EWM, and the high dependence of EWM on respiratory deaths $[1,2]$ suggest that EWM may be able to shed additional insight into this issue.

Indeed, to the present there have been only a few studies on the long-term trends in EWM or investigation into other trends which may lie hidden in the EWM value.

This study seeks to conduct such analysis to see if EWM can be also used to detect the net effects of influenza vaccination or whether other trends could be confounding the association.

In this study EWM is calculated as the average deaths in the four 'winter' months (usually December to March in the temperate parts of the northern hemisphere) versus the average deaths in the previous eight 'non-winter' months (usually April to November) [1]. To further generalize the applicability of this method the calculation is performed as a rolling calculation, i.e, move forward one month and re-calculate. This allows EWM to be more accurately determined in winters with an early or late influenza outbreak, and for countries in the southern hemisphere or nearer to the equator [1]. This is a simple method which can be widely applied across multiple world countries but gives answers comparable to more complex methods such as Serfling, etc [10]. Even Serfling and other models make assumptions regarding the shape of the winter baseline. In EWM deaths are total all-cause mortality, which avoids ambiguity in the assignment of cause of death, and influenza deaths are a subset of EWM - although a key contributor to EWM, i.e, estimated influenza deaths cannot exceed excess winter deaths [1].

\section{Materials and Methods}

\subsection{Monthly deaths}

Monthly deaths are available from 1960 onward for European Union countries via Eurostat [11], and wider data for many world countries is available from 1980 onward via the United Nations [12]. Data for the USA from 1900 to 2004 was provided by Peter Doshi as part of his study on influenza mortality trends [13]. Missing monthly data for the five years 1905 to 1909 in the US time series was reconstructed from annual totals using typical summer month totals either side of these years as a baseline. Only one of these years shows high EWM. This was supplemented by monthly US data from 2005 onward [14]. Data for Denmark from 1901 onwards was obtained from Stats Denmark [15]. Additional data from 1960 onward was obtained from Stats Singapore [16] and Stats Estonia [17]. Deaths in Puerto Rico are excluded from the total for the USA from 2018 onward, and the full time series for Puerto Rico is reported separately.

\subsection{Adjusting EWM for differences between countries}

All countries are referenced to the USA by adjusting all EWM values such that the median EWM for each country is equal to the median of the USA.

In the USA since the 1960 's, EWM reached a minimum of $4.8 \%$ in the winter of $1973 / 74$ and a maximum of $21 \%$ in the winter of $1975 / 76$ and $22 \%$ in 1998/99. Given that all EWM values in this study have been adjusted to USA-equivalent EWM, individual country values below $5 \%$ have been adjusted to $5 \%$ while values above $22 \%$ have been adjusted to $20 \%$. This prevents undue effects from outlying values which can arise in some 
of the smaller countries. In practice trimming makes little difference to the slope of the trends (below).

\subsection{Influenza doses per 1,000 population}

Influenza dose distribution per 1,000 population from the winter of 1980/81 to 2013/14 was from a series of publications by the MIV Study Group [18-25]. Additional doses distributed for the USA was from the CDC [26] divided by population [27]. A variety of northern hemisphere countries were chosen to reflect a range of low to high vaccination, i.e, former Soviet countries (lowest) to Japan/USA (highest). To accurately quantify the intercept at zero vaccination special emphasis was given to countries with very low vaccination levels. For the Netherlands and Finland, the doses of vaccine were extrapolated back to the winter of 1970/71, and the data for the USA was extended to 2019/20 given vaccine doses available from the US CDC $[26,27]$. The list of countries with ranges in doses distributed is given in Table S1 in the Supplementary Material.

\subsection{Influenza vaccination rates, aged $65+$}

Influenza vaccination rates in those aged $65+$ in the USA up to 2001/02 was from the study of Simonsen et al [28], while more recent data was from the US CDC [29-32]. Data for 60 countries was from the OECD [33], European countries were from the study of Spruijt et al [34], and other sources including the WHO Immunization Data Portal [35-49]. Since elderly vaccination rates are only widely available from 2000 onward a method based on a correlation between doses distributed (Section 2.3 above) and proportion elderly vaccinated in the overlapping period 2000 to 2013 was used to extrapolate backwards before 2000 based on doses distributed. In this method the nominal proportion elderly vaccinated calculated from the regression (above) was matched to the available trend from 2000 onward by adjusting the calculated value (from doses distributed) up or down to match the available trend in actual proportion elderly vaccinated. See Figure A1 in the Appendix. This allowed an extended time series from 1988/89 onward. The list of countries with range in proportion elderly vaccinated is given in Table S2 in the supplementary material.

\subsection{Data Manipulation}

Microsoft Excel was used to manipulate the data and produce the charts. Regression was performed using the Excel 'add trendline' function.

\section{Results}

\subsection{Long-term Trends in EWM}

To show a wider historic picture from 1900 to date, Figure 1 shows EWM for the USA and Denmark over the past 120 years. Several important observations can be made from Figure 1, namely:

1. Both countries show $100 \%$ EWM during the $2018 / 19$ winter of the Spanish flu epidemic, i.e, EWM is directly influenced by, and sensitive to, influenza activity and virulence.

2. While the EWM calculation for Denmark and the USA during the Spanish flu both shows a maximum for the 4-months ending January 1919, the USA shows maximum monthly deaths in October 1918, while maximum deaths in Denmark occurred in November 1918. In terms of the timing for higher Spanish flu deaths Denmark tends to be right skewed while the USA is left skewed. This demonstrates the need for a rolling EWM calculation rather than a static one.

3. In addition, EWM shows more complex trends in both Denmark and the USA, with a localized maximum around 1906-1907 (1900/01 to 1911/12) and a wider maximum centered around the time of the Spanish flu (1911/12 to 1930/31) - by coincidence Spanish flu occurred at a time of high baseline EWM. It should be noted that the emergence of Spanish flu precursor strains appears to have started somewhere around 1911 [50], and 
EWM appears to have correctly identified the timing of re-assortments culminating in the maximum at 1918 [50].

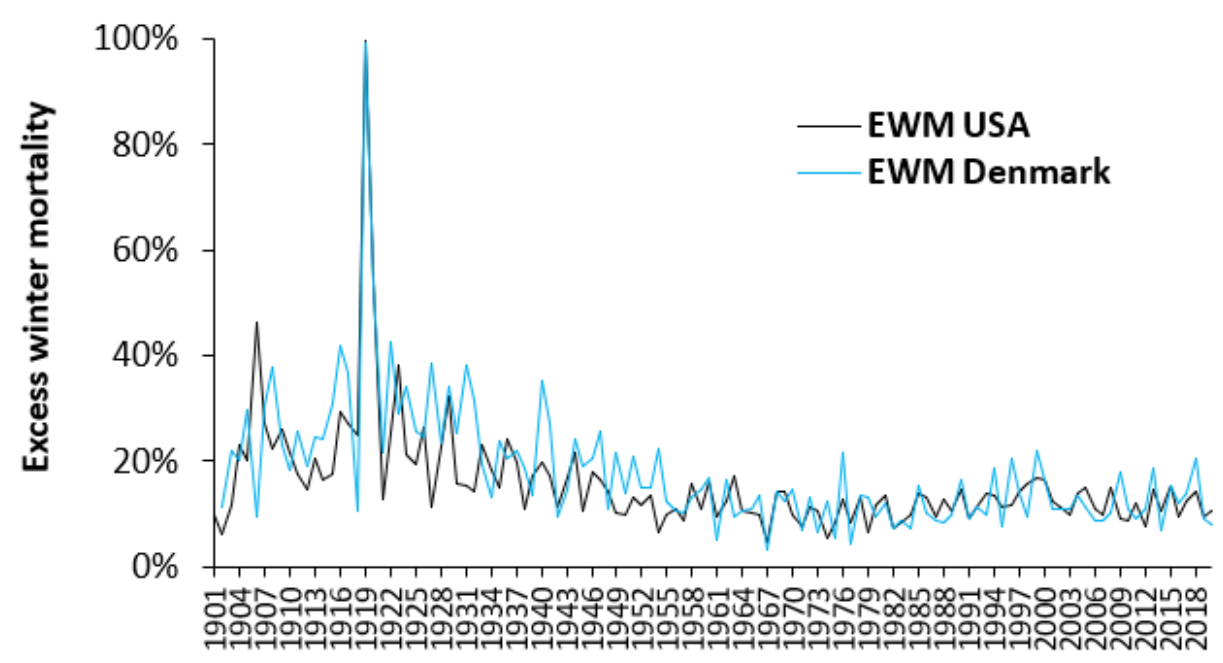

Figure 1. Excess winter mortality (EWM) over the past 120 years in Denmark and the USA.

4. After the Spanish flu, EWM then declined to reach a general minimum in the mid1960 's to 80 's.

5. As an interesting observation there is no evidence that the subsequent flu pandemics of the 1957-58 Asian flu, 1968-69 Hong Kong flu, 1977-79 Russian flu, or the 2009 Swine flu gave rise to unusually high EWM.

6. There was another small peak for the three winters ending 2000 - none of which are pandemics.

Having established the long-term trends in EWM it is relevant to determine how the relative importance of winter may have changed over time.

\subsection{Month in Which EWM Reaches a Maximum}

Given the long-term trend to lower EWM in Figure 1 it is useful to see if the month in which the rolling EWM calculation reaches a maximum has changed over time.

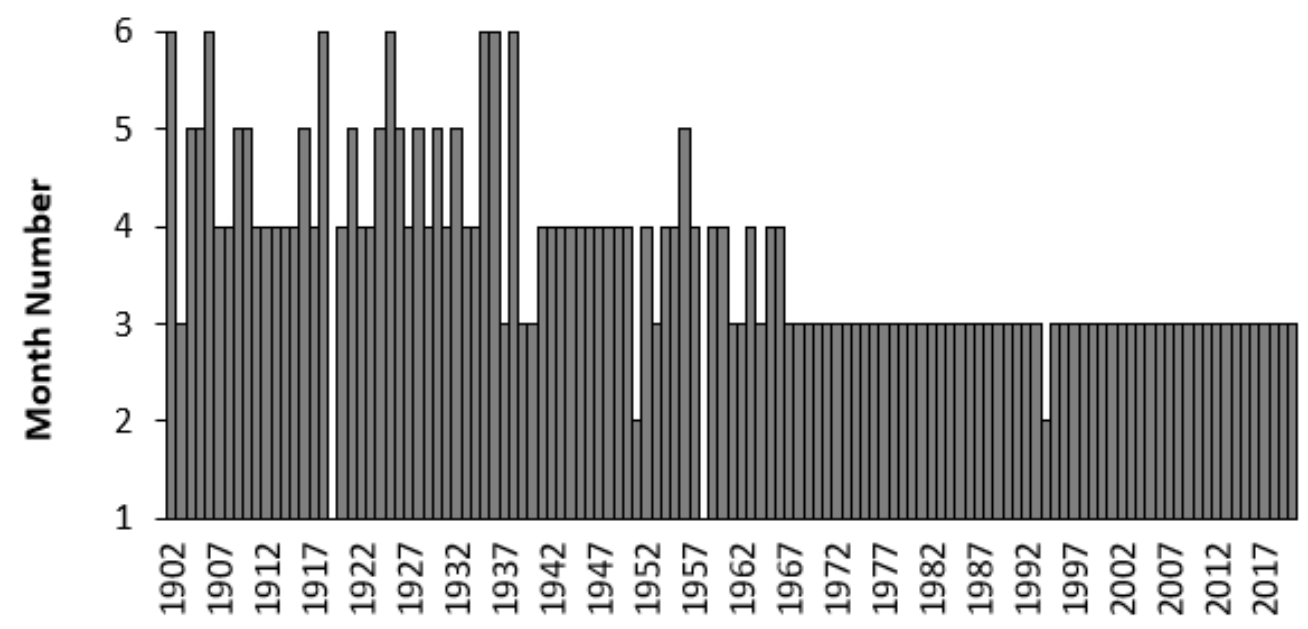

Figure 2. Month of the year at which the rolling EWM calculation reaches its maximum value in Denmark, month 1 = January, etc. 
This is shown in Figure 2 with data from Denmark where the rolling EWM reached a maximum between April to June up to 1935 (autumn excess mortality), then switches to between March and April up to 1966, and beyond that predominantly occurs in March. Two exceptions occur in the winter of 1918/19 and 1957/58 where the maximum EWM occurs in January. The reasons for the seeming sudden transitions remains unknown.

Data for the USA shows a similar transition from April in the early 1900's to March in the late 1960's (data not shown). The transition is more muted than for Denmark because the USA lies further south than Denmark and has a far wider range in latitude.

As an additional observation, using the data on influenza deaths coded to ICD J10 and J11 from the study of Doshi [13] in the USA, reported "influenza" deaths appear to peak across 3 months in the early 1900's moving to 2 months in more recent years (data not shown). A transition appears to occur around the winter of 1967/68 (as also in Figure 2). Additional trends relating to influenza seasonality may lie concealed in the time trends.

\subsection{Winter Deaths are Higher Before the 1970's}

Figure 1 suggests that winter deaths were higher relative to summer deaths in the early 1900's. This is explored for Denmark in Figure 3 where the deaths in each month have been adjusted to equal days per month, and then to the 1995 equivalent number of maximum annual deaths. The Y-axis is truncated at 8,400. Deaths per month merge over time with June and July showing the least change. The seven months June to December show an increase over time, while the five months January to May reduce over time. February, November, and December are the most volatile.

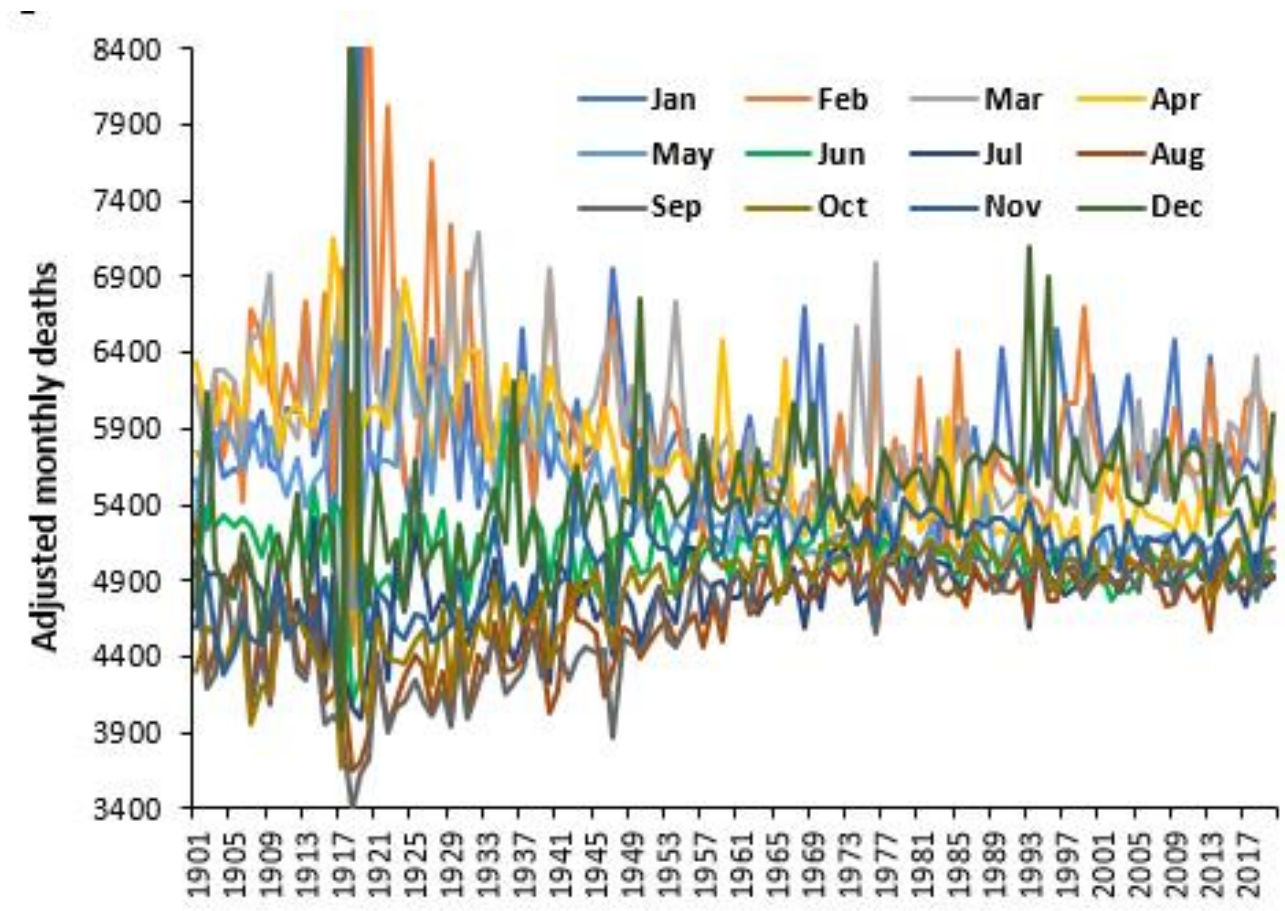

Figure 3. Trend in adjusted monthly deaths in Denmark. Monthly deaths adjusted to give an annual total equal to the maximum achieved in 1995.

Not only have monthly deaths converged but relative volatility may have shifted over time. Hence relative to the period around the time of the Spanish flu deaths have been shifted out of the (moveable) "winter/spring" (January to May) into the "non-winter months". These trends seem to stabilize from the 1970's onward. This explains the reduction in EWM over time seen in Figure 1. Once again, complex trends lie behind the calculated EWM which are poorly understood.

However, it is pleasing to note that the definition of "winter" in the EWM calculation as covering 4 months is sufficiently wide to cover all the obscure trends since the 1900 's. 


\subsection{Similar Trends are Seen in World Countries since the 1960's}

It is useful to see if these trends are replicated wider than just Denmark and the USA and Figure 4 shows data for a wide selection of countries with local EWM converted to the USA-equivalent as per the median-EWM method in section 2.5.

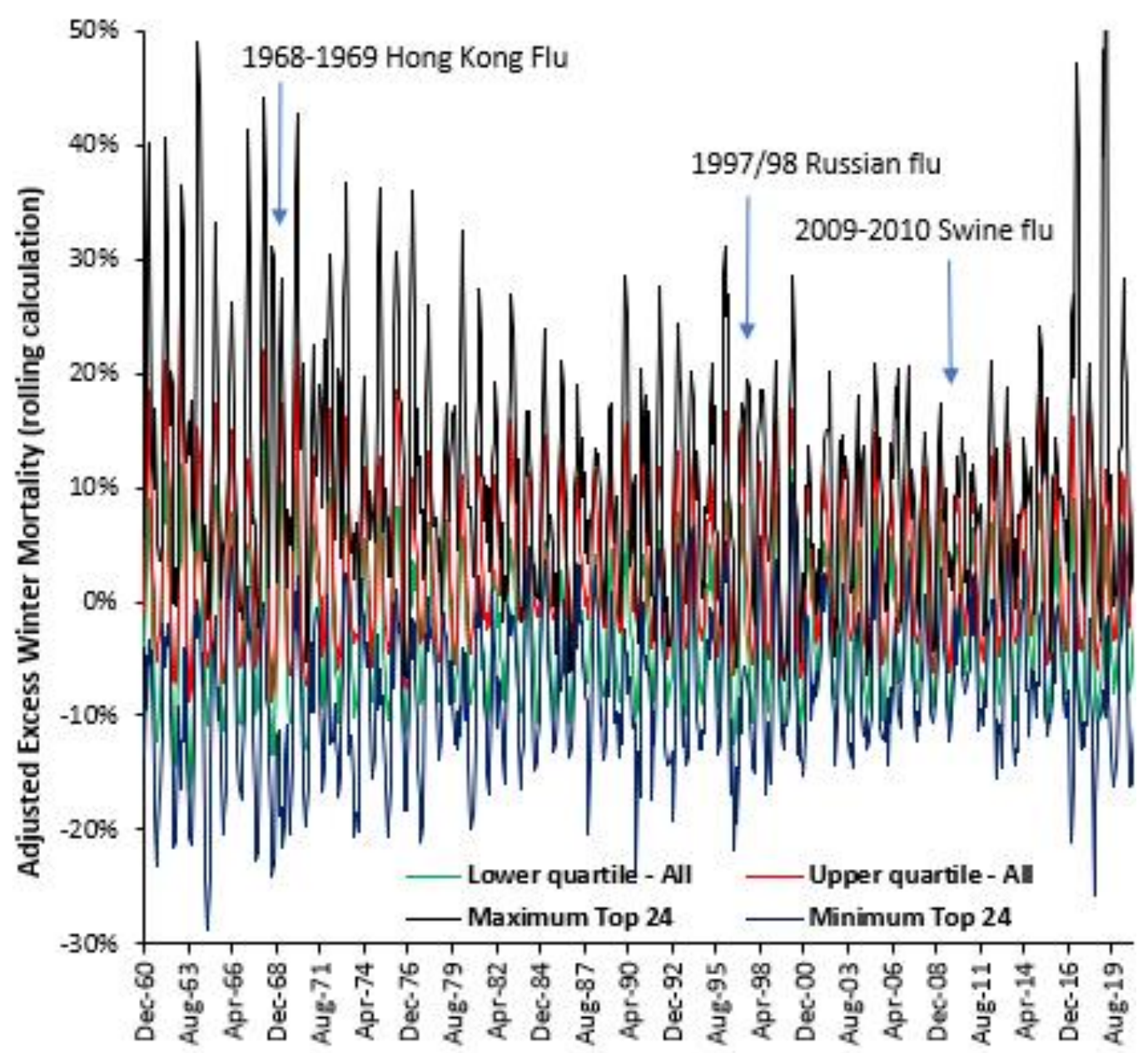

Figure 4. Trend in adjusted EWM for 112 countries, 1960 to 2020.

In Figure 4 the maximum and minimum rolling EWM is shown for the 24 countries with continuous data from 1960 onward, while the upper and lower quartile is shown for a far wider group of up to 112 countries for the years in which data is available. EWM data for countries in the southern hemisphere has been shifted forward by six months to give the northern hemisphere equivalent.

As can be seen there is no evidence for unusually high EWM during the three influenza pandemics occurring over this time frame. The early years of this chart pick up on the end of the downward trend seen in Figure 1. Considerable spatiotemporal variation can be seen in all years, although in general countries move up and down together. Hence the data in Figure 1 is more widely applicable than just Denmark and the USA.

Figure A2 (appendix) shows the proportion of excess winter deaths (EWD) due to "influenza" (ICD codes J10 to J11) in the USA from the winter of 1900/01 to 2003/04. Data is from the study of Doshi [13]. As can be seen this proportion reaches a maximum of $70 \%$ during the Spanish flu pandemic, but regularly goes as high as 50\% up to the mid-1940's. More widespread availability of penicillin from 1945 onward could be one possible reason for the shift down after the mid-1940s. There are complex long-term undulations but no indication that the epidemic years after the Spanish flu have higher deaths than seasonal influenza. This will be covered further in Section 4.4 . 


\subsection{EWM Correlates Well With Calculated Influenza Deaths}

Given that influenza was the major winter pathogen over these years it is useful to see if EWM correlates with estimates of influenza deaths. Such a relationship is demonstrated in Figure 5 using data from Denmark where the FluMOMO European-wide methodology has been employed for the estimated influenza deaths. This is the most advanced methodology which uses weekly deaths after adjustment for the effect of cold temperature extremes. Three different methods are used with influenza-like-illness (ILI), etc, described in the study of Nielson et al [51]. The line for the Goldstein Index probably gives the most reliable estimate of influenza deaths. However, all three lines give good correlation and EWM explains $>85 \%$ (as R-squared) of the observed variation in estimated influenza deaths. As similar chart is available for data from Canada using data from the study of Schanzer et al [52] and is given in the Appendix as Figure A3.

It can therefore be concluded that in all influenza pandemics, other than the Spanish flu, influenza deaths are about the same as expected from seasonal influenza. See discussion regarding role of antigenic distance.

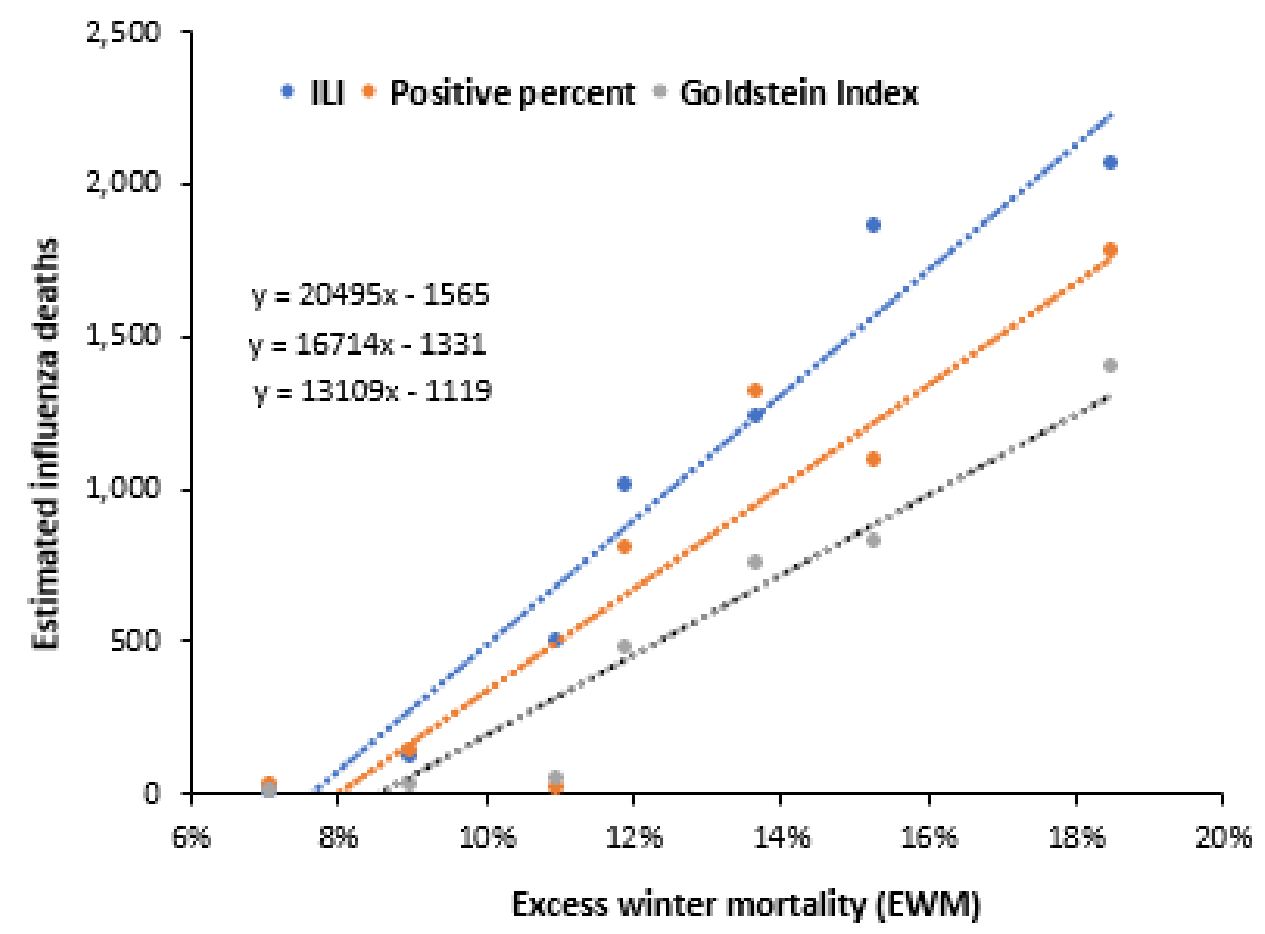

Figure 5. Three different methods for estimating influenza deaths in Denmark, 2010/11 to 2016/17. Influenza deaths are from the study of Nielson et al [51]. FluMOMO data was adjusted for excess deaths arising from periods of very cold weather. The Goldstein Index method is considered the most reliable method. R-squared for the 3-methods ranges from 0.851 (Positive percent), 0.9178 (Goldstein) to 0.9482 (ILI).

\subsection{Is the effect of influenza vaccination detectable using EWM?}

Given that influenza was the major winter pathogen over the period of this study it is interesting if rising international influenza vaccination levels are associated with any change in EWM over time. This issue was addressed in two ways. In the first EWM was plotted against influenza vaccine doses distributed per 1,000 population (see Figure A4 in the Appendix). Data was available from 1980 to 2013. A slight trend to higher EWM was seen, however, there was no statistical difference from the null hypothesis, namely, no change. A list of countries with associated data ranges is given in Table S1 in the Supplementary material.

In the second method EWM was plotted against proportion age 65+ vaccinated and this is shown in Figure 6. 


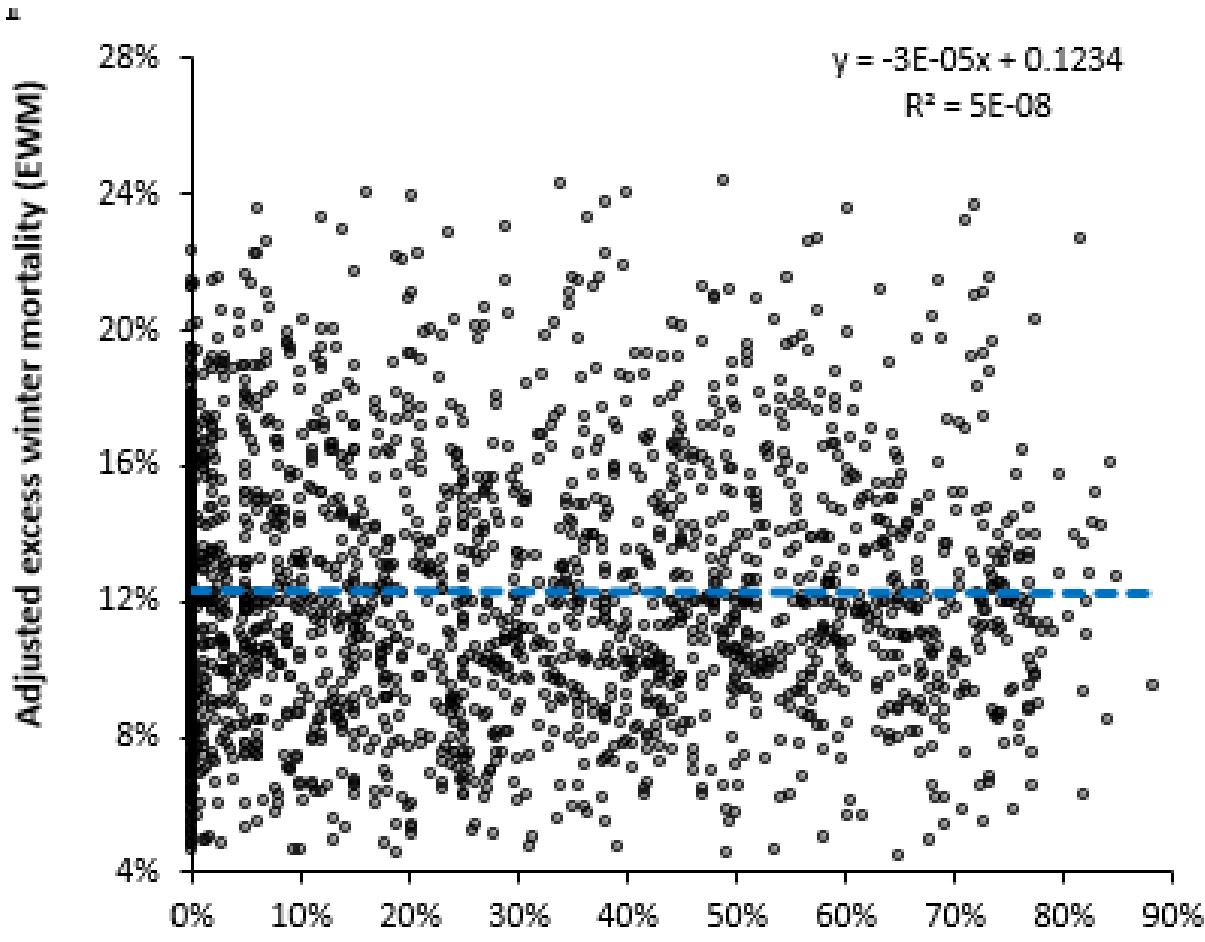

Proportion vaccinated aged $65+$

Figure 6. Adjusted EWM versus proportion aged 65+ vaccinated in 97 countries, 1988/89 to 2019/20.

Data was available from 1988 to 2019/20 for 97 countries. A slight negative slope was seen, however, there was no statistical difference to the null hypothesis. A list of countries with associated data ranges is given in Table S2 in the Supplementary material. In both Figures the R-squared is very low indicating that factors other than influenza vaccination control the observed variation.

During the period of the study there have been trends in multimorbidity, polypharmacy and obesity which are acting to oppose influenza vaccination and these and other trends are discussed in Section 4.5.

\subsection{Is influenza vaccination masking a trend to poor health in the USA?}

Figure 6 could be concealing a trend upward for EWM in some countries. Given the fact that the USA has among the highest levels of obesity, diabetes, and cancer in the developed world (see Section 4.5) we postulated that EWM may be trending upward over time in the US and that influenza vaccination may be masking the extent of this trend. This is illustrated in Figure 7 where the maximum possible effect of influenza vaccination has been estimated to be a $10 \%$ (percentage point) reduction in EWM for a $100 \%$ vaccinated population at $100 \%$ VE. However, in the USA the average VE for persons aged $65+$ has only been $40 \%$ [53], and so the blue dots represent the likely maximum possible EWM in the absence of any vaccination.

As can be seen there is indeed a trend upward in EWM since the 1960's $(0.02 \%$ per annum) and that this trend would be around 3-times higher ( $0.07 \%$ per annum) if there were no influenza vaccination. The two dotted lines are $5^{\text {th }}$ order polynomial curve fits to show that the fundamental trends are probably far more complex, however, these lie around the approximate upward linear trends indicative of declining population health over time. 


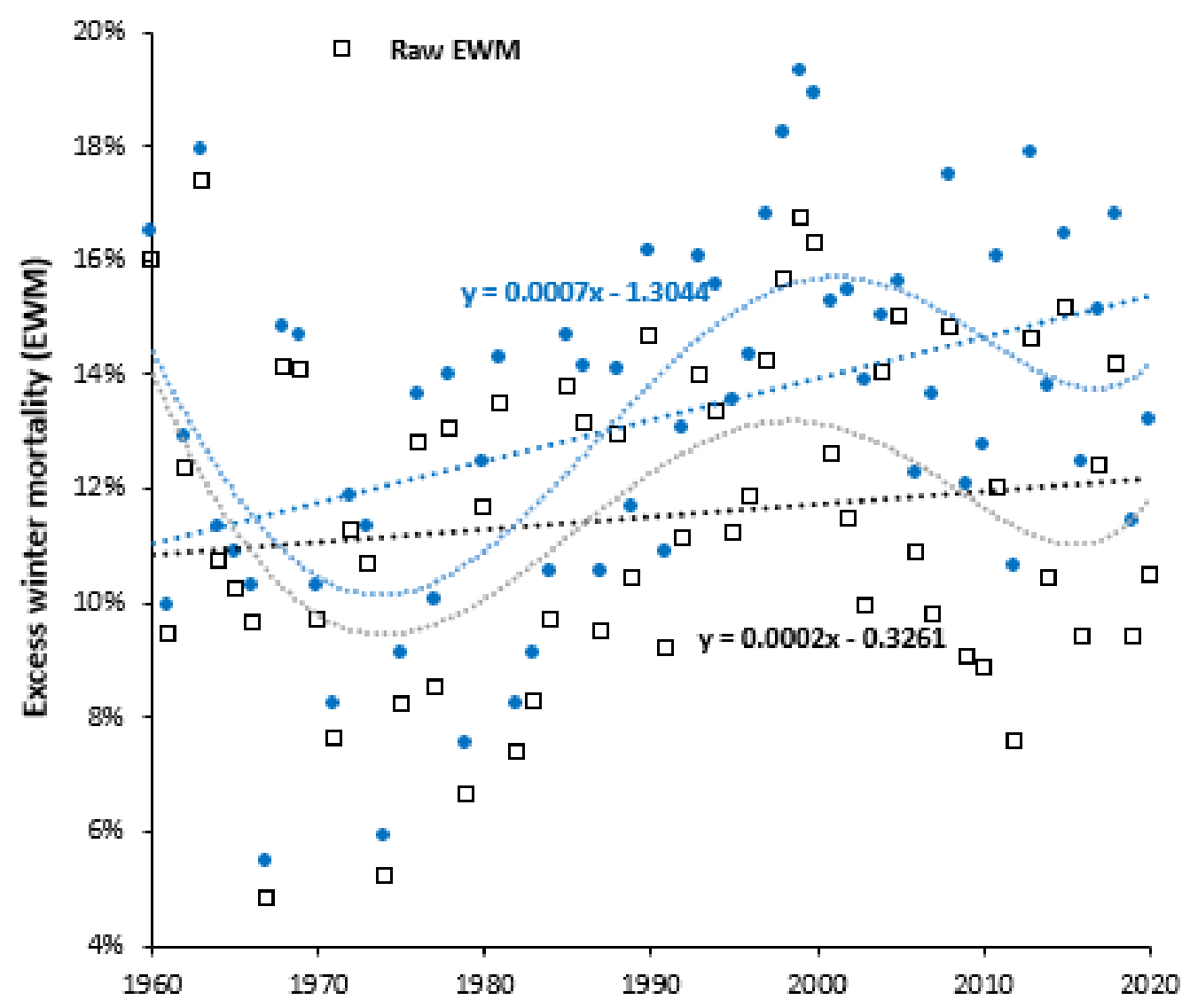

Figure 7. Trend in excess winter mortality (EWM) in the USA from 1960 to 2020, with and without correction for the effect of influenza vaccination. Vaccine effectiveness estimated at $40 \%$, actual VE values for 2003/04 onward [53]. Percent elderly vaccinated increases from around $15 \%$ in the early 1960 's [28] rising to $67 \%$ to $70 \%$ from 2001 onward [29-32].

The US population is seemingly paying a high price for the factors fueling obesity and related morbidities, which in terms of excess winter deaths is being masked by widespread influenza vaccination. Discussed in Section 4.5.

\section{Discussion}

\section{1.. Long-term trends in EWM}

This study has revealed that there are multiple complex biological long-term trends influencing EWM. Figure 1 shows evidence for long-term cycles with a minimum EWM in the early 1900's, a maximum around 1906 and then another minimum around 1911, and a further minimum around the mid-1960's. The work of Smith et al [50] has identified that Spanish flu precursor strains appear to have emerged somewhere around 1911, and EWM appears to have correctly identified the timing of re-assortments culminating in the maximum at 1918 [50].

Note that after the Spanish flu, EWM declines during the pre-antibiotic era. This decline is most likely to be due to improvements in sanitation, refuse collection, health literacy, improved nutrition, and other general improvements in public health, building standards [54,55], and finally the eradication of widespread respiratory tuberculosis via BCG vaccination after World War 2 [56]. Both countries then reach a broad minimum in EWM between the mid-1960's and 1970's.

A shift in deaths out of winter into summer was demonstrated in Denmark. A somewhat similar shift from 1968 to 2018 has been observed in Australia seemingly prompted by some very hot summers induced by global warming [57]. 
The curious trends in the timing and magnitude of winter deaths observed in Figures 2 and 3 are reflected in the timing of maximum EWM revealed by the rolling EWM calculation. While such trends are occurring, they seem to have reached an asymptote from 1967 onward. This at least removes one unknown confounding factor from the analysis conducted in Figures 6 and A3.

A reduction in the difference between summer and winter deaths has also been observed in older people in Sweden over the period 1860 to 1995 [58]. About 40\% of increased life expectancy at age 60 could be attributed to the decrease in seasonality. The main part of the reduction in seasonality was observed to occur between 1870 to 1970 , the latter date being somewhat close to the 1980 date in Denmark when the shift reached an asymptote. In 1860 most of the population lived in the country engaged in agriculture and forestry while by 1970 Sweden was a prosperous country with a highly developed welfare system with most of the population living in cities [58].

Every country will therefore have a different context in which such changes are occurring.

\subsection{EWM is sensitive to influenza deaths}

Figure 5 and A2 suggest that EWM is explaining $>85 \%$ of the observed variation in estimated influenza deaths, and hence, there is every reason to believe that EWM has correctly identified the fact that influenza pandemics since the Spanish flu have not generated any excess deaths over and above that from seasonal influenza as seen in Figures 1 and 4 .

Also note that somewhat paradoxically EWM is highest midway between the poles and the equator [1]. This is simply because countries near the equator experience minimal temperature variation and those nearest the poles are better prepared for winter, i.e, the issues are wider than just external winter temperature [1,2]. This has wider implications to the estimation of global influenza deaths both during pandemics and for seasonal influenza which are discussed in Sections 4.4 and 4.5 .

\subsection{The EWM adjustment factor}

As a rule, EWM reaches a maximum at approximately midway between the equator and the poles $\left(45^{\circ}\right)$ - for example, Spain, France, Croatia, Serbia, Romania, Ukraine, northern Italy, and the most northern US states (northern hemisphere), and New Zealand, and parts of Chile and Argentina (southern hemisphere) [1]. The USA has a generally low international value of EWM. One of the most prominent reasons is its sheer size and range in latitude ( 24 to $49 \circ \mathrm{N}$ ) which means that the spatiotemporal variability of EWM at the state level is moderated. The resulting variation in timing and magnitude leads to offsets creating the appearance of low EWM at national level. EWM adjustment is therefore required to bring other countries to a comparable value to that for the USA - as the country with the longest time series of both EWM and influenza vaccination.

The adjustment factors for the countries are a complex mix of geographic size (as for the USA), latitude, altitude, microclimate, housing standards, access to health care, population age structure, relative wealth and amount of fuel poverty for winter heating [1]. All of these combine to determine the median EWM for each country. The most obvious adjustment, namely using median EWM, has been used in this study.

It is acknowledged that the use of median EWM has limitations and Figure S2 shows long-term trends in EWM for 4 countries. The difference in the trends relative to the USA are unlikely to have a major impact on the scatter seen in Figures 6 and A4 since the available data for these Figures only started in the 1980's.

4.4. Evidence for seasonal levels of influenza deaths during subsequent pandemics

This anomaly between estimated pandemic deaths and recorded influenza deaths was first noted by Doshi [13]. Put simply, influenza deaths are a subset of EWM and reported 'higher' pandemic deaths may be an artefact of the methods used to estimate influenza deaths [3-9,59], or due to reporting bias where deaths during the pandemics are not compared to non-pandemic years. 
It has been proposed that the very high mortality seen during the Spanish flu pandemic arose from previous exposure during the 1889-90 Asiatic flu pandemic. This led to a very high mortality peak at the exact age of 28 [59]. Original antigenic sin or antigenic imprinting during the earlier Asiatic flu then led to immune dysregulation during exposure to a highly dissimilar variant/clade during the Spanish flu [59].

This can work in the other direction, and two notable examples exist where pandemic influenza did not increase deaths due to antigenic imprinting. The 1977-79 Russian flu pandemic was antigenically similar to strains circulating in 1947 to 1956 [60,61], and antigenic imprinting created pre-existing immunity and low deaths, as demonstrated in Figures 1 and 4. The same holds for the 2009 Swine flu pandemic $[62,63]$ in which there were very few elderly deaths due to childhood exposure to similar strains, as also seen in Figures 1 and 4 .

The issue is not the 'pandemic' designation but antigenic distance from previous lifetime exposure [64-68]. As demonstrated in Figure 1, seemingly only the Spanish flu met the antigenic distance criteria. The problem seems to be one of selective reporting of pandemic deaths without comparison to other years, of which 2017/18 is but one example where influenzas type B were unusually high, there was a vaccine mismatch due to a shift in dominant clades [69], and consequently VE was generally low [70,71].

Regarding the issue of pandemic influenza deaths from Figure 1 it should be noted that other studies have commented upon the apparent absence of higher influenza deaths during pandemics compared to seasonal influenza [71] - Spanish flu excepted. It was proposed that the wider publicity surrounding pandemics may have led doctors to code more hospital admissions and deaths to influenza/pneumonia thereby artificially inflating the estimates of influenza deaths [71].

Some comment needs to be made regarding the study of Peter Doshi [13] which investigated trends in recorded influenza mortality (ICD codes J10 and J11). Doshi was fully aware that ICD codes J10/J11 underestimate total influenza mortality, however, his study used these codes as a common denominator to explore the trend over time, i.e, there is no a priori reason for doctors to record fewer J10/J11 as cause of death over time. Trends in recorded influenza deaths in his study and observed for EWM in Figure 1 of this study both decline over time, and do not show undue deaths during pandemics after the Spanish flu. This point was further emphasized in Figure A2.

Also note that EWM is highest midway between the poles and the equator and reaches an absolute minimum at the equator [1]. Countries nearest the poles are better prepared for winter [1], i.e, the issues are wider than just external winter temperature. (see Section 4.5).

International estimates of influenza deaths do not account for the role of latitude in moderating EWM and deaths, and overestimation of deaths is likely. Most of Africa is equatorial or sub-equatorial and will have a low EWM (although monthly data is absent for most of Africa and even annual deaths are estimated). As demonstrated in Figure 5 the method developed in FluMOMO using the Goldstein Index probably gives the most reliable basis. The method based on ILI is least reliable because ILI is caused by multiple pathogens and usually less than $35 \%$ of persons with ILI test positive for influenza [7275]. The method currently used in the USA by the CDC appears to overestimate influenza deaths by around 30\% (See Figure S1 in the Supplementary material [76-81]. The USA is so large and covers such a wide range in latitude that monthly or weekly deaths in each state can be converted to EWM or a FluMOMO equivalent. The FluMOMO algorithms are open source [7].

4.5. EWM and influenza vaccination - competing underlying trends

In 1945 the first inactivated influenza vaccine became available for public use [82]. Most advanced economies start to increase influenza vaccination during the 1980's [1825]. According to the WHO by 2000 only 20 countries had policies for seasonal influenza vaccination, rising to 91 in 2010 and 124 in 2020 [83], hence, higher levels of vaccination in the elderly only generally occur beyond 2000. In 2000 elderly vaccination rates ranged up 
to $76 \%$ in the Netherlands (the majority below $65 \%$ ), to a maximum of $86 \%$ in 2019 for South Korea (the majority below $70 \%$ ) $[12,83]$.

Influenza vaccination is known to reduce both hospitalization and death in the elderly [84] and should act to reduce EWM. Several studies have estimated that influenza vaccination should make a detectable effect upon EWM $[28,85]$. The fact that Figures 6 and A4 do not demonstrate any downward trend raises the question as to whether the effect of influenza vaccination is being counterbalanced by other trends. Figure 7 investigated this possibility using EWM data from the USA which is possibly the developed country with the worst morbidity trends. It was proposed that rising morbidity was causing EWM to rise by a maximum possible upper limit of $0.07 \%$ per annum (in the absence of influenza vaccination) and that increasing influenza vaccination over time led to the observed lower value of $0.02 \%$ per annum increase.

The issues around rising morbidity is explored in Table 1 where increases in multimorbidity, polypharmacy, obesity, Alzheimer's and dementia, and age at death will all contribute to pressure to increase EWM since the 1980's. Several factors contributing to lower EWM are also discussed.

Table 1. Factors increasing or decreasing EWM with time

\section{Factors Increasing EWM with time}

Multimorbidity - Levels of basic and complex multimorbidity have been increasing over time [86,87]. Multimorbidity is associated with diminished response to influenza vaccination [88] and risk of influenza mortality [89].

Polypharmacy - Polypharmacy in the Netherlands and USA had more than doubled in the interval 1999 to 2014 [90]. Certain pharmaceuticals and polypharmacy alter the immune response to influenza vaccination [91]. Polypharmacy has been found to be a risk factor for hospitalization, and death from COVID-19 [92] and for pneumonia admissions for nursing home residents $[93,94]$.

Obesity - has been increasing over time [87]. It creates systemic inflammation, reduces B-cell function [95,96], generates auto-immune antibodies during infection [97], and interferes with influenza vaccination efficiency $[98,99]$.

Alzheimers and dementia - Incidence increases exponentially with age [100] and are a significant risk factor for influenza mortality [101].

Diabetes - Incidence increases with age [102] and is a significant risk factor in influenza mortality [103]. In the USA persons aged 65+ experienced the greatest increase in the incidence of diabetes since 1988 [102]. However

\section{Factors reducting EWM with time}

Home insulation - this is a major contributor to reductions in winter hospitalization and mortality in some countries [115-121]. The greatest benefit will occur in countries midway between the poles and equator which tend to have housing suited to summer rather than winter [1].

Increased access to health care (critical care, antibiotics, antivirals, etc) and wider public health measures [1,2] - this will mainly apply to the less developed countries.

Reduced smoking prevalence - smoking prevalence is declining in the developed world [121]. Smoking leads to inflammation and is a risk factor in influenza mortality $[123,124]$.

Improvements in influenza vaccine technology such as cell versus egg grown vaccines [125,126].

Influenza vaccination in the elderly increased vaccination will lead to lower influenza deaths [84], especially in years with a high VE. 


\begin{tabular}{|l|l|}
\hline Factors Increasing EWM with time & Factors reducting EWM with time \\
\hline $\begin{array}{l}\text { mortality is reduced by influenza vaccination } \\
{[104,105] .}\end{array}$ & \\
\hline $\begin{array}{l}\text { Cancer - Cancer incidence increases with age } \\
{[106] \text { with incidence especially high in the US }} \\
{[106] . \text { Cancer survivors are at far higher risk of }} \\
\text { influenza mortality [107]. Mortality is reduced } \\
\text { by influenza vaccination [108] }\end{array}$ & $\begin{array}{l}\text { Ghould be more mild leading to lower EWM } \\
\text { withe. Although this will be moderated by } \\
\text { long-term adaption such that the temperature } \\
\text { for minimum mortality is very close to the } \\
\text { most frequently experienced temperature } \\
\text { [127]. }\end{array}$ \\
\hline
\end{tabular}

Air pollution (especially in large cities with population growth) - Air pollution is well recognized for its ability to increase systemic inflammation [109], alter aspects of immune function [110], increase incidence of ILI [111], and increase the proportion of persons infected with influenza [112]. It also interferes with influenza vaccination efficiency and is a risk factor for influenza mortality [113]. In children, air pollution has an adverse effect on lung function which is moderated by influenza vaccination [114].

Longeivity or increasing age at death - EWM increases with age at death, however, difficult to assess over many decades as chronological age is not a good measure of biological or epigenetic age [1]. Chronological age will also be serving as a proxy for the above factors.

Age at death is probably the greatest contributor to higher EWM [1] and in England and Wales the proportion of persons dying at age 65+ has risen since 1980 from $82 \%$ to $88 \%$ (in 2019) in females and from $71 \%$ to $82 \%$ in males [128]. Age will also be serving as a proxy for many of the morbidity issues. Since 1980 average age at death over the age of 65 has risen from 76 to 81 in males and 80 to 85 in females [128]. Age will be intertwined with multimorbidity, polypharmacy, etc.

These forces are opposed by improvements in home insulation, reduced smoking prevalence, improvements in influenza technology and more widespread influenza vaccination in the elderly.

There have not been any studies looking at how all the factors may (synergistically) combine to change EWM over time, and thereby diminish the ability of influenza vaccination to reduce EWM. All these trends will be country specific, and it is suggested that the analysis in Figures 6 and A4 be repeated for each country to disentangle the multiple trends.

The role of temperature is more problematic. The temperature for minimum deaths in each location is very close to the most frequent temperature experienced in that location [127]. Deaths respond far more to extreme temperature events [129]. Hence, it has been noted that although deaths increase as it gets colder, temperature alone only explains a small amount of the variation in EWM between years [130]. There are complex interactions between air pollution (PM10), temperature and influenza on all-cause, respiratory, and cardiovascular mortality [131]. Each of these variables operates both alone (PM10 mainly affects cardiovascular, and influenza affects mainly respiratory) and in combination with additional specific interactions between influenza-PM10 for cardiovascular mortality and between influenza-temperature upon all-cause mortality. The 
relationships are complex and will mostly affect those living in large cities - which usually make a major contribution to total deaths and hence the whole country value of EWM.

Once again, the complex relationships between temperature/air pollution/influenza will be country specific.

Indoor temperature is a known major factor in EWM [115-121], which suggests that it is not influenza per se, but influenza infection exaggerated by poorly maintained indoor temperature which is a contributory factor in deaths. It is extremely difficult to disentangle the two.

\subsection{Strengths and Limitations}

The major strengths of this study are that very long-term trends have been investigated using a method which can be applied to readily available monthly international data. Apart from the Spanish flu pandemic the absence of higher pandemic influenza deaths has been established from multiple perspectives. The ability of influenza vaccination to reduce EWM was investigated with two large data sets, however, these lacked information on the relative effects of the opposing forces. The role of competing trends was highlighted, but quantifying these trends was beyond the scope of the study.

The method based on median EWM to adjust all countries to the US equivalent could potentially suffer from country-specific trends in EWM which are different from those in the US. It is also possible that additional complexity between countries lies at annual level.

\section{Conclusions}

EWM is a simple but powerful way of investigating the role of multiple and complex trends over time. 'Winter' has seemingly moved from the four months ending April/May in the early 1900's to ending March in more recent times. Deaths have seemingly been shifted out of winter as time has progressed, but in the two developed countries studied this had seemingly reached an asymptote by the mid-1960's. Higher influenza deaths during pandemics (except the Spanish flu) have been discounted on multiple fronts, and the role for antigenic distance was highlighted. The seeming lack of effect against EWM due to rising influenza vaccination has raised the possibility that increasing age at death and increasing aspects of elderly morbidity are acting to obscure any trend. The exact contribution of the opposing trends needs to be quantified.

Supplementary Materials: The following supporting information can be downloaded at: www.mdpi.com/xxx/s1, Table S1: Summary of data relating to each country included in the influenza vaccine doses distributed analysis.; Table S2: Summary of data relating to each country $(n=98)$ included in the proportion elderly vaccinated study. Figure S1: US CDC estimated flu deaths (adjusted for growth in deaths over time) versus EWM. Figure S2: Trend in EWM for Denmark, Iceland, Singapore, and Sweden over the 60-year period 1960 to 2020.

Author Contributions: Conceptualization, RJ; methodology, RJ; validation, RJ; formal analysis, RJ; investigation, RJ; data curation, RJ; writing-original draft preparation, RJ.; writing-review and editing, AP.

Funding: This research received no external funding.

Institutional Review Board Statement: Not applicable.

Informed Consent Statement: Not applicable

Data Availability Statement: All data is publicly available. Data compiled for this study is available on request from Dr Rodney Jones, email: hcaf_rod@yahoo.co.uk

Conflicts of Interest: The authors declare no conflict of interest. 


\section{Appendix A}

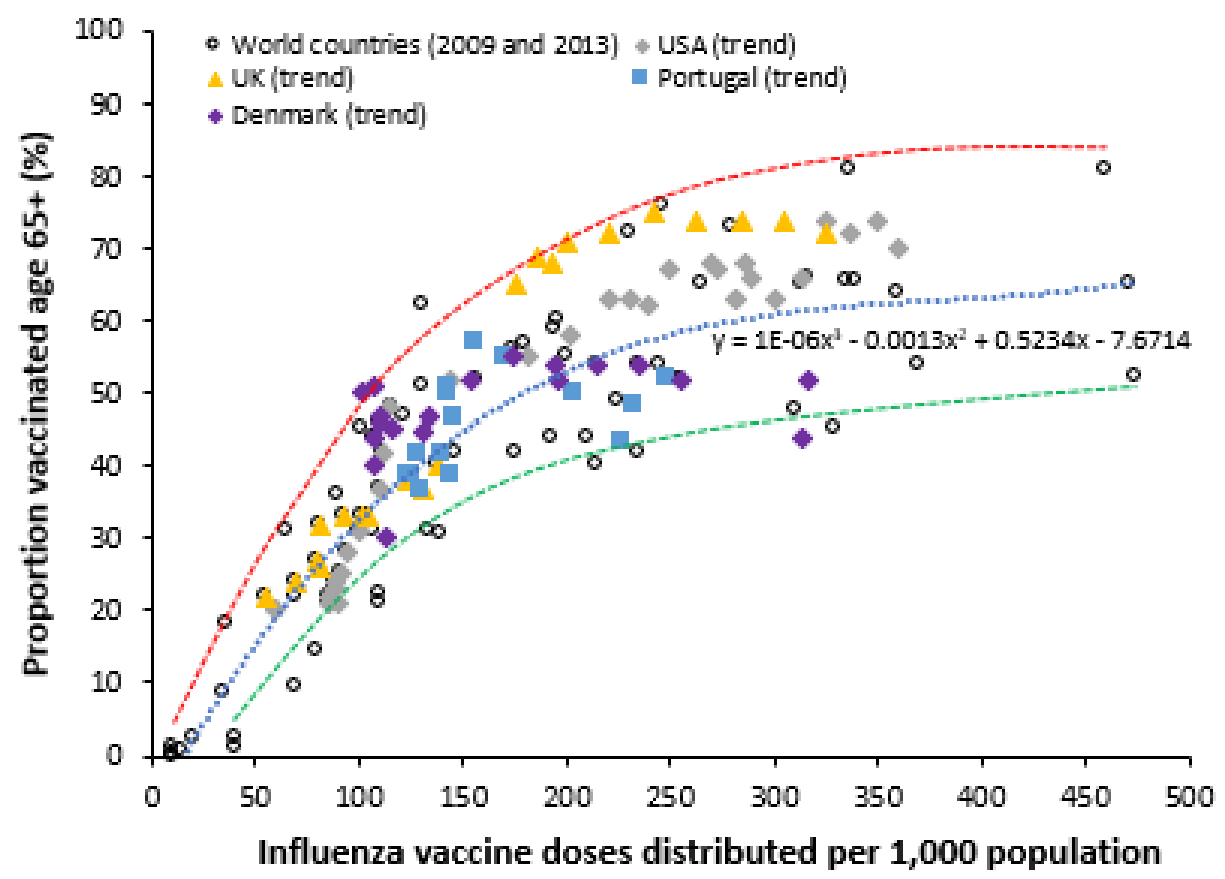

Figure A1. Relationship between influenza doses distributed and proportion vaccinated in various countries (2009-2013) and the time trend for 4 countries (2000 onward). Red and green dashed lines are the upper and lower limit. The blue dotted line is the line of best fit using a third order polynomial. Before 2000 the bulk of countries lie below 150 doses per 1,000 population.

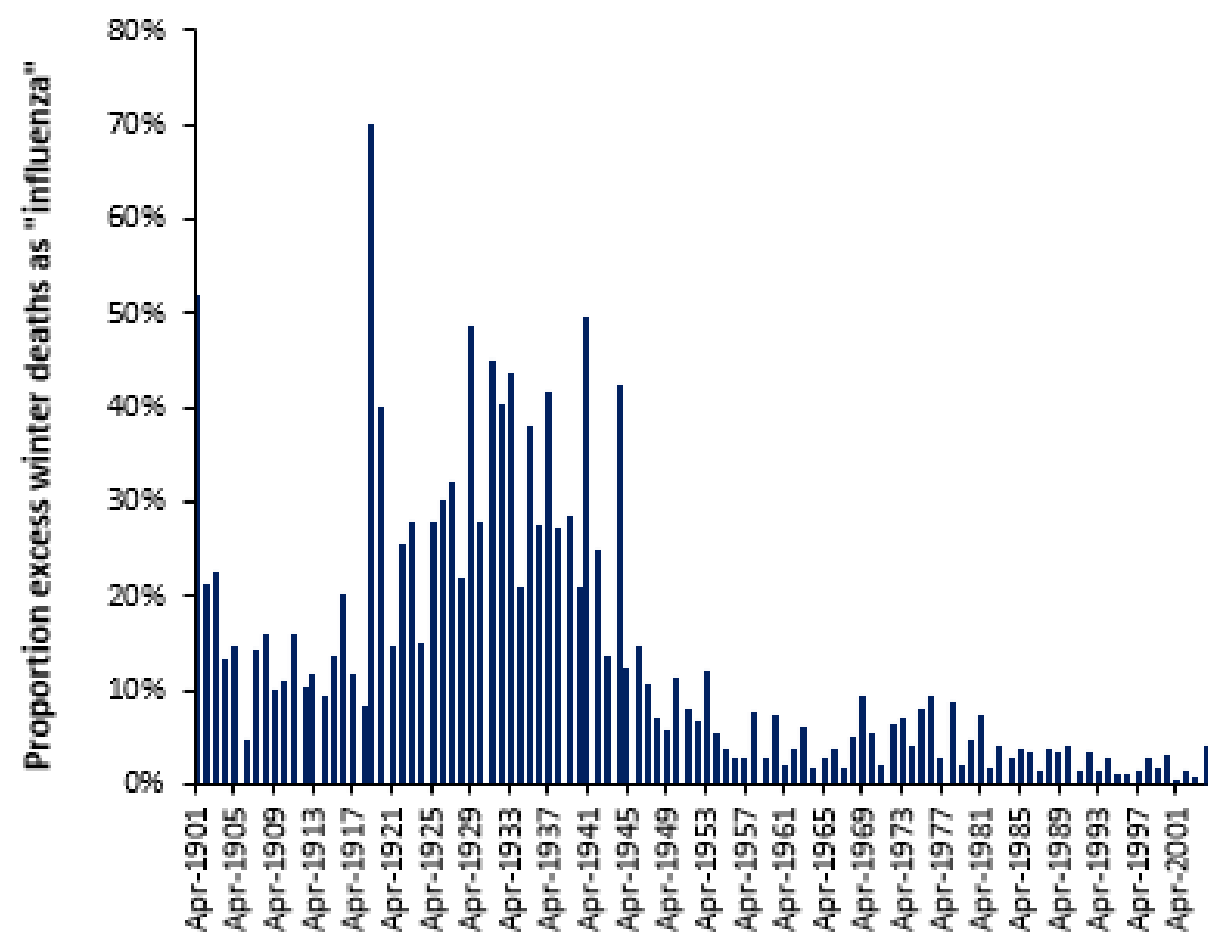

Figure A2. Proportion of excess winter deaths (EWD) recorded as "influenza" (ICD codes J10 and J11). Data is from the study of Doshi [13]. Coding practice seem to have changed from 1977 onward and the proportion after this date has been multiplied by 1.8 to compensate. 


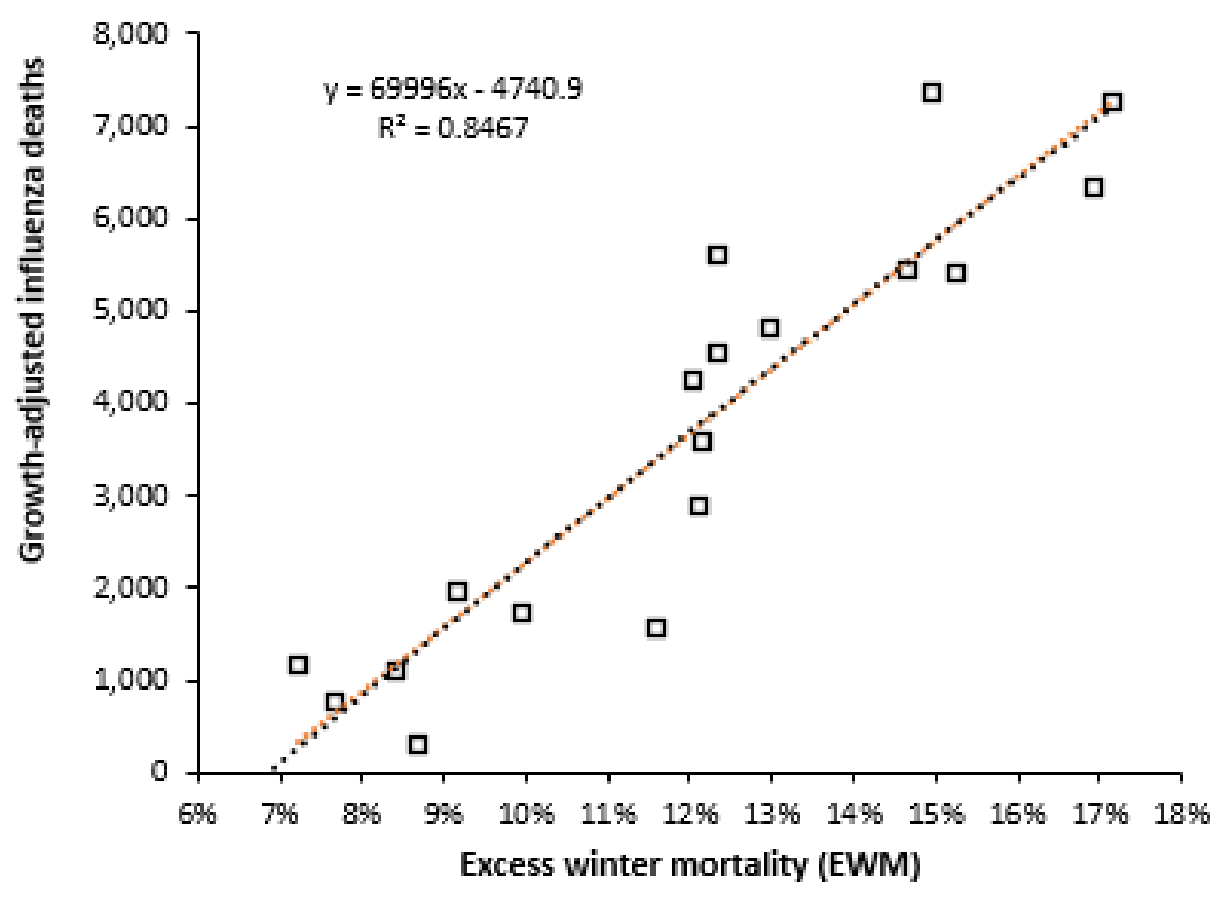

Figure A3. Relationship between estimated influenza deaths in Canada versus EWM, 1992-2009. Data is from the study of Schanzer et al [50]. From 1992 to 2009 there was around 19\% growth in deaths. Each year has been adjusted for underlying growth using a polynomial curve fit.

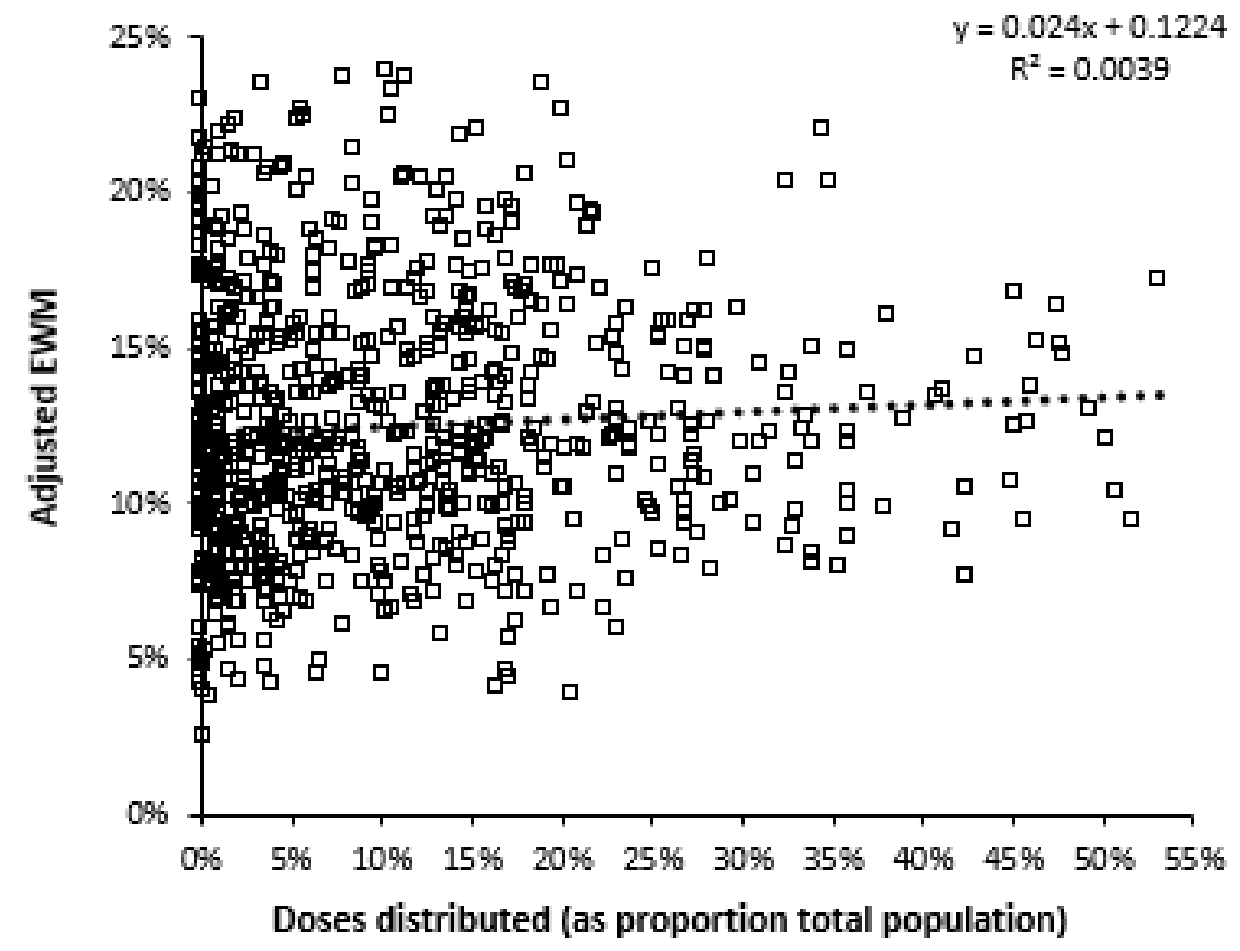

Figure A4. Relationship between influenza doses distributed and adjusted EWM over the winters 1980/81 to 2013/14 (before trimming of high/low values). Trimming of high/low values makes little difference (data not shown). Before 2013/14 the bulk of countries lie below 200 doses per 1,000 population (20\% vaccinated). Dividing the data into three groups of high/medium/low vaccination $(17 \%$ increments of proportion vaccinated) gives overlapping confidence intervals, and the null hypothesis cannot be excluded. i.e, the slope is zero (data not shown) or no effect can be discerned. 


\section{References}

1. Jones R. Excess winter mortality (EWM) as a dynamic forensic tool, Where, when, which conditions, gender, ethnicity, and age. IJERPH 2021; 18(4), 2161. doi: 10.3390/ijerph18042161

2. Healy J. Excess winter mortality in Europe: a cross country analysis identifying key risk factors. J Epidemiol Commun Health 2003; 57: 784-789. doi: 10.1136/jech.57.10.784

3. Glezen W. Emerging infections: Pandemic influenza. Epidemiol Rev 1996; 18(1): 64-76.

4. Meltzer M, Cox N, Fukuda K. The economic impact of pandemic influenza in the United States: priorities for intervention. Emerg Infect Dis. 1999;5(5):659-671. doi:10.3201/eid0505.990507

5. Nicoll A, Ciancio B, Lopez C, et al. Influenza-related deaths - available methods for estimating numbers and detecting patterns for seasonal and pandemic influenza in Europe . Euro Surveill. 2012;17(18):pii=20162. https://doi.org/10.2807/ese.17.18.20162-en

6. Muscatello D, Newall A, Dwyer D, MacIntyre C. Mortality attributable to seasonal and pandemic influenza, Australia, 2003 to 2009, Using a novel time series smoothing approach. PLOS ONE 2013; 8(6): e64734. https://doi.org/10.1371/journal.pone.0064734

7. EuroMOMO. FluMOMO. FluMOMO - EUROMOMO (accessed 14 January 2022)

8. Rolfes M, Foppa I, Garg S, et al. Annual estimates of the burden of seasonal influenza in the United States: A tool for strengthening influenza surveillance and preparedness. Influenza Other Respir Viruses. 2018;12(1):132-137. doi:10.1111/irv.12486

9. Paget J, Spreeuwenberg P, Charu V, et al. Global mortality associated with seasonal influenza epidemics: New burden estimates and predictors from the GLaMOR Project. J Glob Health. 2019; 9(2):020421. doi: 10.7189/jogh.09.020421.

10. Serfling R. Methods for current statistical analysis of excess pneumonia-influenza deaths. Public Health Rep. 1963;78(6):494506.

11. Eurostat, Deaths (total) by month. Statistics I Eurostat (europa.eu) Accessed 11 November 2021

12. UNData. Deaths by month of death. UNdata I record view I Deaths by month of death Accessed 11 November 2021

13. Doshi P. Trends in recorded influenza mortality, United States, 1900-2004. Am J Public Health. 2008, 98(5), 939-945. doi: 10.2105/AJPH.2007.119933. Erratum in, Am J Public Health. 2009, 99(8), 1353-1354.

14. CDC National Vital Statistics System. Monthly and 12 month-ending number of live births, deaths and infant deaths, United States. . State and National Provisional Counts (cdc.gov) Accessed 11 November 2021

15. Statistics Denmark. Live births and deaths by movement and time. Available online: Statistikbanken (statbank.dk)(accessed on 16 April 2021)

16. Statistics Singapore. Deaths by ethnic group and sex, monthly. ( (DOS) I SingStat Table Builder - Deaths By Ethnic Group And Sex Accessed 14 January 2022

17. Statistics Estonia. Monthly deaths. Deaths I Statistikaamet

18. Fedson D, Hannoun C, Leese J, et al. Influenza vaccination in 18 developed countries, 1980-1992. Vaccine 1995, $13(7), 623-627$. doi: 10.1016/0264-410x(94)00041-k.

19. Fedson D, Hirota Y, Shin H, et al. Influenza vaccination in 22 developed countries, an update to 1995. Vaccine 1997, 15(14), 1506-1511. doi: 10.1016/s0264-410x(97)00091-1.

20. Ambrosch F, Fedson D. Influenza vaccination in 29 countries. An update to 1997. Pharmacoeconomics. 1999, 16(Suppl 1), 4754. doi: 10.2165/00019053-199916001-00007.

21. van Essen G, Palache A, Forleo E, Fedson D. Influenza vaccination in 2000: recommendations and vaccine use in 50 developed and rapidly developing countries._Vaccine 2003; 21(16): 1780-1785. doi: 10.1016/S0264-410X(03)00072-0.

22. Macroepidemiology of Influenza Vaccination (MIV) Study Group. The macroepidemiology of influenza vaccination in 56 countries, 1997-2003. Vaccine 2005, 23, 5133-5143.

23. Palace, A. Seasonal Influenza Vaccine Provision in 157 Countries (2004 to 2009) and the Potential Influence of National Public Health Policies. Vaccine 2011, 29, 9459-9466. doi: 10.1016/j.vaccine.2011.10.030

24. Palache A, Oriol-Mathieu V, Abelin A, et al. Seasonal influenza vaccine dose distribution in 157 countries (2004-2011). Vaccine. 2014, 32(48), 6369-6376. doi: 10.1016/j.vaccine.2014.07.012.

25. Palache A, Oriol-Mathieu V, Fino M, et al. Seasonal influenza vaccine dose distribution in 195 countries (2004-2013), Little progress in estimated global vaccination coverage. Vaccine. 2015, 33(42), 5598-5605. doi: 10.1016/j.vaccine.2015.08.082.

26. CDC. Historical Reference of Seasonal Influenza Vaccine Doses Distributed. Historical Reference of Seasonal Influenza Vaccine Doses Distributed I CDC

27. Macrotrends. US population growth rate 1950 - 2021. https,//www.macrotrends.net/countries/USA/united-states/populationgrowth-rate. Accessed 11 November 2021

28. Simonsen L, Reichert T, Viboud C, et al. Impact of influenza vaccination on seasonal mortality in the US elderly population. Arch Intern Med 2005, 165(3), 265-272. doi:10.1001/archinte.165.3.265

29. Centers for Disease Control and Prevention (CDC). Influenza vaccination coverage trends, 1989 to 2008. Available online: NHIS89_08fluvaxtrendtab.pdf (cdc.gov) (accessed on 8 February 2021).

30. CDC. Influenza vaccine coverage, adults aged 65 years and older, United States. Influenza Vaccination Coverage, Adults 65 Years and Older, United States I FluVaxView I Seasonal Influenza (Flu) I CDC Accessed 11 November 2021.

31. Centers for Disease Control and Prevention. Flu Vaccination Coverage, United States, 2018-19 Influenza Season. Available online: Flu Vaccination Coverage, United States, 2018-19 Influenza Season | FluVaxView | Seasonal Influenza (Flu) | CDC (accessed on 30 April 20210. 
32. CDC. Flu Vaccination Coverage, United States, 2019-20 Influenza Season. Available online:Flu Vaccination Coverage, United States, 2019-20 Influenza Season | FluVaxView | Seasonal Influenza (Flu) | CDC (accessed on 8 February 2021)

33. OECD Data. Influenza vaccination rates (full indicator data). Health care use - Influenza vaccination rates - OECD Data Accessed 14 January 2022

34. Spruijt, I.T, Lang, M. de Dijkstra, F, et al. Long-term correlation between influenza vaccination coverage and incidence of influenza-like illness in 14 European Countries. PLoS One 2016, 11(9), e0163508.

35. WHO. Influenza vaccination data base. Influenza vaccination coverage (who.int) Accessed 14 January 2022

36. World Health Organisation. Influenza vaccination coverage, elderly. 2020.Available online: Influenza vaccination coverage, elderly - European Health Information Gateway (who.int) (accessed on 8 February 2021)

37. Public Health England. Green Book of Immunization. Chapter 19 Influenza, 2020. The Green book of immunisation - chapter 19 influenza (publishing.service.gov.uk)

38. Public Health Wales. Annual influenza surveillance and influenza vaccination uptake reports: 2003-2020. Available online: Public Health Wales Health Protection Division - Annual influenza surveillance and influenza vaccination uptake reports: 2003-2020 (accessed 12 Mar 2021)

39. Jorgensen P, Mereckiene J, Cotter S, et al. How close are countries of the WHO European Region to achieving the goal of vaccinating $75 \%$ of key risk groups against influenza? Results from national surveys on seasonal influenza vaccination programmes, 2008/2009 to 2014/2015. Vaccine 2018; 36(4): 442-452. https://doi.org/10.1016/j.vaccine.2017.12.019.

40. ECDC. Seasonal influenza vaccination in Europe - Vaccination recommendations and coverage rates for eight influenza seasons (2007-2008 to 2014-2015). 20 July 2017. Available online: Seasonal influenza vaccination in Europe - Vaccination recommendations and coverage rates for eight influenza seasons (2007-2008 to 2014-2015) (europa.eu).Accessed on 25 February 2021

41. Blank P, Schwenkglenks M, Szucs T. The impact of European vaccination policies on seasonal influenza vaccination coverage rates in the elderly. Human Vaccines \& Immunotherapeutics, 2012; 8:3, 328-335, doi: 10.4161/hv.18629

42. Blank P, Schwenkglenks M, Szucs T. Influenza vaccination coverage rates in five European countries during season 2006/07 and trends over six consecutive seasons. BMC Public Health 2008; 8, 272. https://doi.org/10.1186/1471-2458-8-272

43. Korkmaz P, PaşaliKilit T, Onbaşi K, et al. Influenza vaccination prevalence among the elderly and individuals with chronic disease, and factors affecting vaccination uptake. Cent Eur J Public Health. 2019; 27(1): 44-49. doi: 10.21101/cejph.a5231.

44. Beard F, Hendry A, Macartney K. Influenza vaccination uptake in our most vulnerable groups: how well are we protecting them in 2019? Commun Dis Intell 2020; 44: https:/doi.org/10.33321/cdi.2020.44.27

45. Newspoll Omnibus Survey. Summary Report Flu Vaccinations Department of Health Newspoll Ref: 14060423 June 2014. report-newspoll-flu-vaccinations-survey-jun-2014.pdf (health.gov.au)

46. Zürcher K, Zwahlen M, Berlin C, et al. Losing ground at the wrong time: trends in self-reported influenza vaccination uptake in Switzerland, Swiss Health Survey 2007-2017. BMJ Open 2021;11:e041354. doi: 10.1136/bmjopen-2020-041354

47. Singapore Ministry of Health. National population health survey 2019. Available online: national-population-health-survey2019.pdf (hpb.gov.sg)(accessed on 17 February 2021)

48. Kwon D, Kim K, Park S. Factors associated with influenza vaccination coverage among the elderly in South Korea: the Fourth Korean National Health and Nutrition Examination Survey (KNHANES IV) BMJ Open 2016; 6: e012618. doi: 10.1136/bmjopen-2016-012618

49. González-Block M, Gutiérrez-Calderón E, Pelcastre-Villafuerte B, et al. Influenza vaccination hesitancy in five countries of South America. Confidence, complacency and convenience as determinants of immunization rates. PLOS ONE 2020; 15(12): e0243833. https://doi.org/10.1371/journal.pone.0243833

50. Smith G, Bahl J, Vijaykrishna D, et al. Dating the emergence of pandemic influenza viruses. Proc Nat Acad Sci 2009, 106(28), 11709-11712. doi: 10.1073/pnas.0904991106

51. Nielsen J, Krause T, Mølbak K. Influenza-associated mortality determined from all-cause mortality, Denmark 2010/11-2016/17: The FluMOMO model. Influenza Other Respir Viruses 2018, 12(5), 591-604. doi: 10.1111/irv.12564.

52. Schanzer DL, Sevenhuysen C, Winchester B, Mersereau T. Estimating influenza deaths in Canada, 1992-2009. PLOS ONE 2013; 8(11): e80481. doi: 10.1371/journal.pone.0080481

53. CDC. CDC seasonal flu vaccine effectiveness studies. CDC Seasonal Flu Vaccine Effectiveness Studies I CDC Accessed 25 January 2022.

54. Achievements in Public Health, 1900-1999, Changes in the Public Health System. JAMA 2000, $283(6)$, 735-738. doi:10.1001/jama.283.6.735

55. Woods R. Mortality and sanitary conditions in the "Best governed city in the world" - Birmingham, 1870-1910. J Historical Geog 1978, 4(1),35-56. doi: 10.1016/0305-7488(78)90069-5.

56. Daniel T. The history of tuberculosis. Resp Med 2006, 100(11), 1862-1870. doi: 10.1016/j.rmed.2006.08.006.

57. Hanigan I, Dear K, Woodward A. Increased ratio of summer to winter deaths due to climate warming in Australia, $1968-2018$. Aust N Z J Public Health. 202; 45(5): 504-505. doi: 10.1111/1753-6405.13107.

58. Ledberg A. A large decrease in the magnitude of seasonal fluctuations in mortality among elderly explains part of the increase in longevity in Sweden during 20th century. BMC Public Health. 2020; 20(1): 1674. doi:10.1186/s12889-020-09749-4 
59. Thomas R. Are influenza-associated morbidity and mortality estimates for those $\geq 65$ in statistical databases accurate, and an appropriate test of influenza vaccine effectiveness? Vaccine. 2014, 32(51), 6884-6901. doi: 10.1016/j.vaccine.2014.08.090.

60. Gagnon A, Miller MS, Hallman SA, et al. Age-specific mortality during the 1918 influenza pandemic, unravelling the mystery of high young adult mortality. PLoS One 2013, 8(8), e69586. doi: 10.1371/journal.pone.0069586

61. Grinbaum E, Ivanova N, Luzianina T, et al. Antigennaia i biologicheskaia kharakteristika virusov grippa A1, izolirovannykh v pandemiiu $1977 \mathrm{~g}$ [Antigenic and biological characteristics of influenza A1 viruses isolated in the 1977 pandemic]. Vopr Virusol. 1979, May-Jun, (3), 232-236.

62. Rozo M, Gronvall GK. The Reemergent 1977 H1N1 Strain and the Gain-of-Function Debate. mBio 2015, 6(4), e01013-15. Published 2015 Aug 18. doi:10.1128/mBio.01013-15

63. Adalja AA, Henderson D. Original Antigenic Sin and pandemic (H1N1) 2009. Emerg Infect Dis 2010, 16(6), 1028-1029. Doi: 10.3201/eid1606.091653

64. Henry C, Palm A-K, Krammer F, Wilson P. From original antigenic sin to the universal influenza virus vaccine. Trends in Immunol 2018, 39(1),70-79. doi: 10.1016/j.it.2017.08.003.

65. Wu A, Peng Y, Du X, Shu Y, Jiang T. Correlation of influenza virus excess mortality with antigenic variation: application to rapid estimation of influenza mortality burden. Plos Computational Biology. 2010 Aug;6(8). DOI: 10.1371/journal.pcbi.1000882.

66. Gupta V, Earl DJ, Deem MW. Quantifying influenza vaccine efficacy and antigenic distance. Vaccine. 2006;24(18):3881-3888. doi:10.1016/j.vaccine.2006.01.010

67. Sitaras I. Antigenic Cartography: Overview and Current Developments. Methods Mol Biol. 2020;2123:61-68. doi: 10.1007/978-10716-0346-8_5.

68. Anderson CS, McCall PR, Stern HA, Yang H, Topham DJ. Antigenic cartography of H1N1 influenza viruses using sequencebased antigenic distance calculation. BMC Bioinformatics. 2018 Feb;19(1):51. DOI: 10.1186/s12859-018-2042-4.

69. Wu A, Peng Y, Du X, Shu Y, Jiang T. Correlation of influenza virus excess mortality with antigenic variation, application to rapid estimation of influenza mortality burden. Plos Computational Biology 2010, 6(8). DOI: 10.1371/journal.pcbi.1000882.

70. Kawakami C, Yamayoshi S, Akimoto M, et al. Genetic and antigenic characterisation of influenza A(H3N2) viruses isolated in Yokohama during the 2016/17 and 2017/18 influenza seasons. Euro Surveill 2019, 24(6), 1800467. doi: 10.2807/15607917.ES.2019.24.6.1800467.

71. CDC. Summary of the 2017-2018 influenza season. Summary of the 2017-2018 Influenza Season I CDC Accessed 27 November 2021.

72. Thomas R. Is influenza-like illness a useful concept and an appropriate test of influenza vaccine effectiveness? Vaccine 2014, 32(19), 2143-2149. https,//doi.org/10.1016/j.vaccine.2014.02.059.

73. Bollaerts K, Antoin J, Van Casteren V, et al. Contribution of respiratory pathogens to influenza-like illness consultations. Epidemiol Infect 2013, 141(10), 2196-2204.

74. Pretorius M, Tempia S, Walarza S, et al. The role of influenza, RSV and other common respiratory viruses in severe acute respiratory infections and influenza-like illness in a population with a high HIV sero-prevalence, South Africa 2012-2015. J Clin Virol 2016, 75, 21-26. https,//doi.org/10.1016/j.jcv.2015.12.004.

75. Brunstein J, Cline C, McKinney S, Thomas E. Evidence from multiplex molecular assays for complex multipathogen interactions in acute respiratory infections. J Clin Micro 2008, 46(1), 97-102.

76. Thompson W, Moore M, Weintraub E, et al. Estimating influenza-associated deaths in the United States. Am J Public Health. 2009;99 Suppl 2(Suppl 2):S225-S230. doi:10.2105/AJPH.2008.151944

77. CDC. Disease burden of flu. Disease Burden of Flu I CDC Accessed 15 December 2021

78. CDC. Estimates of deaths associated with seasonal influenza --- United States, 1976-2007. MMWR 2010, 59(33), 1057-1062.

Estimates of Deaths Associated with Seasonal Influenza --- United States, 1976--2007 (cdc.gov)

79. CDC. How many adults die from flu each year? Frequently Asked Questions about Estimated Flu Burden I CDC Accessed 15 December 2021

80. CDC. Summary of the 2011-2012 influenza season. Summary of the 2011-2012 Influenza Season I CDC Accessed 15 December 2021.

81. CDC. Summary of the 2014-2015 influenza season. Summary of the 2014-2015 Influenza Season I CDC Accessed 15 December 2021

82. CDC. Influenza historic timeline. Influenza Historic Timeline | Pandemic Influenza (Flu) | CDC Accessed 31 January 2022.

83. WHO. Introduction of seasonal influenza vaccine. Introduction of Seasonal Influenza vaccine (who.int) Accessed 16 January 2022.

84. Walzer, P.; Estève, C.; Barben, J.; et al. Impact of Influenza Vaccination on Mortality in the Oldest Old: A Propensity ScoreMatched Cohort Study. Vaccines 2020, 8, 356. https://doi.org/10.3390/vaccines8030356

85. Rizzo C, Viboud C, Montomoli E, Simonsen L, Miller MA. Influenza-related mortality in the Italian elderly, no decline associated with increasing vaccination coverage. Vaccine. 2006 Oct 30,24(42-43),6468-75. doi: 10.1016/j.vaccine.2006.06.052.

86. Head A, Fleming K, Kypridemo C, et al. Inequalities in incident and prevalent multimorbidity in England, 2004-19: a population-based, descriptive study. The Lancet Healthy Longevity 2021; 2(8): e489-e497. https://doi.org/10.1016/S26667568(21)00146-X.

87. Lebenbaum M, Zaric G, Thind A, Sarma S. Trends in obesity and multimorbidity in Canada. Prevent Med 2018; 116: 173-179. Doi: 10.1016/j.ypmed.2018.08.025. 
88. McElhaney J, Kuchel, Zhou X, et al. Cell Immunity to Influenza in Older Adults: A Pathophysiological Framework for Development of More Effective Vaccines. Front Immunol 2016; 7: 41. Doi: 10.3389/fimmu.2016.00041

89. Gutiérrez-González E, Cantero-Escribano J, Redondo-Bravo L, et al. Effect of vaccination, comorbidities and age on mortality and severe disease associated with influenza during the season 2016-2017 in a Spanish tertiary hospital. J Infect Public Health 2019; 12(4): 486-491. https://doi.org/10.1016/j.jiph.2018.11.011.

90. Oktora M, Denig P, Bos J, et al. Trends in polypharmacy and dispensed drugs among adults in the Netherlands as compared to the United States. PLOS ONE 2019; 14(3): e0214240. doi: 10.1371/journal.pone.0214240

91. Agarwal D, Schmader K, Kossenkov A, et al. Immune response to influenza vaccination in the elderly is altered by chronic medication use. Immun Ageing. 2018; 15: 19. doi: 10.1186/s12979-018-0124-9.

92. Sorochi I, Osaro M, Ekere J. Polypharmacy among COVID-19 patients: A systematic review. J Amer Pharm Assoc 2021; 61(5): e14-e25. doi: 10.1016/j.japh.2021.05.006.

93. Frazier S. Health outcomes and polypharmacy in elderly individuals: an integrated literature review. J Gerontol Nurs. 2005 Sep;31(9):4-11. doi: 10.3928/0098-9134-20050901-04

94. Lin, C, Chang, Y, Tsou, M. et al. Factors associated with hospitalization for community-acquired pneumonia in home health care patients in Taiwan. Aging Clin Exp Res 32, 149-155 (2020). https://doi.org/10.1007/s40520-019-01169-8

95. Frasca D, Ferracci F, Diaz A, et al. Obesity decreases B cell responses in young and elderly individuals. Obesity, 2016; 24: 615625. doi: 10.1002/oby.21383

96. Frasca D, Diaz A, Romero M, Blomberg B. Phenotypic and functional characterization of double negative B cells in the blood of individuals with obesity. Front Immunol 2021; 12: doi: 10.3389/fimmu.2021.616650

97. Frasca, D, Reidy, L, Romero, M. et al. The majority of SARS-CoV-2-specific antibodies in COVID-19 patients with obesity are autoimmune and not neutralizing. Int J Obes 2021; 7: 1-6 . doi: 10.1038/s41366-021-01016-9

98. Sheridan $\mathrm{P}$, Paich $\mathrm{H}$, Handy J, et al. Obesity is associated with impaired immune response to influenza vaccination in humans. Int J Obes 36, 2012; 1072-1077. doi: 10.1038/ijo.2011.208

99. Livio L, Radaelli M. Influenza and obesity: its odd relationship and the lessons for COVID-19 pandemic. Acta Diabetologica 2020; 57(6): 759-764.

100. Corrada M, Brookmeyer R, Paganini-Hill A, et al. Dementia incidence continues to increase with age in the oldest old: the 90+ study. Ann Neurol. 2010;67(1):114-121. doi:10.1002/ana.21915

101. Brandeis G, Berlowitz D, Coughlin N. Mortality associated with an influenza outbreak on a dementia care unit. Alzheimer Disease and Associated Disorders. 1998 Sep;12(3):140-145. DOI: 10.1097/00002093-199809000-00004. PMID: 9772015.

102. Cheng Y, Imperatore G, Geiss L, et al. Secular Changes in the Age-Specific Prevalence of Diabetes Among U.S. Adults: 19882010. Diabetes Care 2013; 36(9): 2690-2696. doi: 10.2337/dc12-2074

103. Valdez R, Narayan K, Geiss L, Engelgau M. Impact of diabetes mellitus on mortality associated with pneumonia and influenza among non-Hispanic black and white US adults. American Journal of Public Health 1999; 89(11): 1715-1721.

104. Wang C-S, Wang S-T, Lai C-T, et al. Impact of influenza vaccination on major cause-specific mortality. Vaccine 2007; 25(7): 11961203.doi: 10.1016/j.vaccine.2006.10.015.

105. Schade C, McCombs M. Influenza immunization and mortality among diabetic Medicare beneficiaries in West Virginia. The West Virginia Medical Journal. 2000; 96(3): 444-448.

106. White M, Holman D, Boehm J, et al. Age and cancer risk: a potentially modifiable relationship. Am J Prev Med. 2014;46(3 Suppl 1):S7-S15. doi:10.1016/j.amepre.2013.10.029

107. Carreira H, Strongman H, Peppa M, et al. Prevalence of COVID-19-related risk factors and risk of severe influenza outcomes in cancer survivors: a matched cohort study using linked UK electronic health records data. EClinicalMedicine 2020; 29:100656. doi: 10.1016/j.eclinm.2020.100656

108. Shehata M, Karim N. Influenza vaccination in cancer patients undergoing systemic therapy. Clin Med Insights Oncol. 2014 May 1;8:57-64. doi: 10.4137/CMO.S13774.

109. Chen H, Kaufman J , Olaniyan T, et al. Changes in exposure to ambient fine particulate matter after relocating and long term survival in Canada: quasi-experimental study BMJ 2021; 375 :n2368 doi:10.1136/bmj.n2368

110. Glencross D, Ho T-R, Camiña N, et al. Air pollution and its effects on the immune system. Free Radical Biology and Medicine 2020; 151: 56-68. Doi: 10.1016/j.freeradbiomed.2020.01.179.

111. Lindner-Cendrowska, K, Bröde, P. Impact of biometeorological conditions and air pollution on influenza-like illnesses incidence in Warsaw. Int J Biometeorol 2021; 65, 929-944. Doi: 10.1007/s00484-021-02076-2

112. Lu B, Wang Y, Zhu Z, et al. Epidemiological and genetic characteristics of influenza virus and the effects of air pollution on laboratory-confirmed influenza cases in Hulunbuir, China, from 2010 to 2019. Epidemiol Infect 2020; 148, E159. doi:10.1017/S0950268820001387

113. Wong C, Yang L, Thach T, et al. Modification by influenza on health effects of air pollution in Hong Kong. Environ Health Perspect 2009; 117(2):248-53. doi: 10.1289/ehp.11605.

114. Liu K, Yang B-Y, Guo Y, et al. The role of influenza vaccination in mitigating the adverse impact of ambient air pollution on lung function in children: New insights from the Seven Northeastern Cities Study in China. Environ Res 2020; 187: 109624. doi: 10.1016/j.envres.2020.109624.

115. Preval N, Keall M, Telfar-Barnard L, et al. Impact of improved insulation and heating on mortality risk of older cohort members with prior cardiovascular or respiratory hospitalisations. BMJ Open 2017; 7: e018079. doi: 10.1136/bmjopen-2017-018079 
116. WHO. Housing and health guidelines. Chapter 4: Low indoor temperatures and insulation. 2018. Low indoor temperatures and insulation - WHO Housing and Health Guidelines - NCBI Bookshelf (nih.gov)

117. Huebner GM, Hamilton I, Chalabi Z, et al. Comparison of indoor temperatures of homes with recommended temperatures and effects of disability and age, an observational, cross-sectional study. BMJ Open 2018, 8, e021085. doi: 10.1136/bmjopen-2017021085

118. Saeki K, Obayashi K, Iwamoto J, et al. Stronger association of indoor temperature than outdoor temperature with blood pressure in colder months. J Hypertens 2014; 32(8): 1582-1589. doi: 10.1097/HJH.0000000000000232.

119. NICE. Excess winter deaths and illness and the health risks associated with cold homes. NICE guideline [NG6], 05 March 2015. 3 Context I Excess winter deaths and illness and the health risks associated with cold homes I Guidance I NICE Accessed 29 December 2021.

120. Hajat S. Evidence review and economic analysis of excess winter deaths. 2015. evidence-review-2-interventions-and-economic-studies-pdf-544621934 (nice.org.uk)_Accessed 29 December 2021.

121. Fyfe C, Telfar L, Barnard, Howden-Chapman P, Douwes J. Association between home insulation and hospital admission rates: retrospective cohort study using linked data from a national intervention programme. BMJ 2020; 371 :m4571 doi:10.1136/bmj.m4571

122. CDC. Current cigarette smoking among adults in the United States. Current Cigarette Smoking Among Adults in the United States I CDC Accessed 24 December 2021.

123. Chavez, J.; Hai, R. Effects of cigarette smoking on influenza virus/host interplay. Pathogens 2021, 10 , 1636. https://doi.org/10.3390/pathogens10121636

124. Godoy P, Castilla J, Soldevila N, et al. Smoking may increase the risk of influenza hospitalization and reduce influenza vaccine effectiveness in the elderly, European Journal of Public Health, 2018; 28(1): 150-155. doi: 10.1093/eurpub/ckx130

125. Pawelec G, McElhaney J. Recent advances in influenza vaccines. F1000Res. 2020;9:F1000 Faculty Rev-305. Published 2020 Apr 28. doi:10.12688/f1000research.22611.1

126. Tsilibary E-P, Charonis S, Georgopoulos A. Vaccines for influenza. Vaccines 2021; 9: 47. doi: 10.3390/vaccines9010047

127. Yin, Q, Wang, J, Ren, Z. et al. Mapping the increased minimum mortality temperatures in the context of global climate change. Nat Commun 2019; 10, 4640. https://doi.org/10.1038/s41467-019-12663-y

128. ONS. Deaths by single year of age tables.

129. Allen MJ, Sheridan SC. Mortality risks during extreme temperature events (ETEs) using a distributed lag nonlinear model. Int J Biometeorol. 2018; 62(1): 57-67. doi: 10.1007/s00484-015-1117-4.

130. ONS. Excess winter mortality in England and Wales: 2012 to 2013 (provisional) and 2011 to 2012 (final). 26 November 2013. Excess winter mortality in England and Wales - Office for National Statistics (ons.gov.uk)

131. Murtas, R, Russo, A.G. Effects of pollution, low temperature and influenza syndrome on the excess mortality risk in winter 2016-2017. BMC Public Health 19, 1445 (2019). https://doi.org/10.1186/s12889-019-7788-8

132. Gan G, Pang J. Obesity in Singapore: Prevention and control. Singapore Family Physician 2012; 38(8): 71_pdf (cfps.org.sg) Accessed 30 January 2022. 


\section{Supplementary Material}

Table S1. Summary of data relating to each country included in the influenza vaccine doses distributed analysis. The column " $10 \%$ achieved" gives the winter at which $10 \%$ population vaccination coverage was achieved.

\begin{tabular}{|c|c|c|c|c|c|}
\hline \multirow[b]{2}{*}{ Country } & \multirow{2}{*}{$\begin{array}{l}\text { Lati- } \\
\text { tude }\end{array}$} & \multirow{2}{*}{$\begin{array}{l}\text { EWM ad- } \\
\text { justment }\end{array}$} & \multirow{2}{*}{$\begin{array}{r}\text { Data (n) } \\
\text { up to } \\
2013 / 14\end{array}$} & \multicolumn{2}{|c|}{ Vaccination } \\
\hline & & & & Range & $\begin{array}{r}10 \% \\
\text { achieved }\end{array}$ \\
\hline Singapore & 1.3 & 1.650 & 34 & $0 \%-10 \%$ & $2009 / 10$ \\
\hline Hong Kong & 22.3 & 0.656 & 33 & $1 \%-15 \%$ & $2003 / 04$ \\
\hline South Korea & 36.1 & 1.463 & 23 & $5 \%-41 \%$ & $1996 / 97$ \\
\hline Japan & 36.3 & 0.668 & 33 & $0 \%-51 \%$ & $2000 / 01$ \\
\hline USA(!) & 38.0 & 1.000 & 40 & $6 \%-53 \%$ & $1988 / 89$ \\
\hline Turkey & 39.1 & 0.981 & 4 & $3 \%-4 \%$ & No \\
\hline Portugal & 39.6 & 0.443 & 34 & $1 \%-25 \%$ & $1994 / 95$ \\
\hline Greece & 39.7 & 1.150 & 14 & $12 \%-32 \%$ & $2000 / 01$ \\
\hline Armenia & 40.3 & 0.471 & 22 & $0 \%$ & No \\
\hline Spain & 40.4 & 0.590 & 34 & $5 \%-34 \%$ & $1988 / 89$ \\
\hline Macedonia & 41.4 & 0.826 & 21 & $0 \%-1 \%$ & No \\
\hline Kyrgyzstan & 41.5 & 1.600 & 8 & $0 \%$ & No \\
\hline Uzbekistan & 41.8 & 0.979 & 7 & $0 \%-1 \%$ & No \\
\hline Italy & 42.5 & 0.746 & 24 & $15 \%-34 \%$ & $1984 / 85$ \\
\hline Montenegro & 42.8 & 0.993 & 9 & $0 \%-7 \%$ & No \\
\hline Bosnia and Herzegovina & 43.7 & 0.939 & 10 & $0 \%-4 \%$ & No \\
\hline San Marino & 43.9 & 0.453 & 26 & $0 \%-15 \%$ & $2004 / 05$ \\
\hline France & 46.6 & 1.080 & 34 & $9 \%-36 \%$ & $1988 / 89$ \\
\hline Switzerland & 46.8 & 0.900 & 34 & $5 \%-22 \%$ & $1998 / 99$ \\
\hline Austria & 47.6 & 0.996 & 34 & $1 \%-17 \%$ & $1999 / 00$ \\
\hline Kazakhstan & 48.1 & 1.520 & 21 & $2 \%-4 \%$ & No \\
\hline Ukraine & 48.4 & 1.060 & 30 & $0 \%-2 \%$ & No \\
\hline Luxembourg & 49.6 & 0.924 & 12 & $15 \%-48 \%$ & $2004 / 05$ \\
\hline Belgium & 50.6 & 0.854 & 34 & $5 \%-27 \%$ & $1993 / 94$ \\
\hline Germany & 51.9 & 1.200 & 34 & $6 \%-35 \%$ & $1997 / 98$ \\
\hline Poland & 52.1 & 1.040 & 34 & $1 \%-10 \%$ & $2001 / 02$ \\
\hline Netherlands $(\alpha)$ & 52.3 & 1.070 & 44 & $3 \%-46 \%$ & $1994 / 95$ \\
\hline Ireland & 53.2 & 0.738 & 22 & $3 \%-31 \%$ & $2002 / 03$ \\
\hline UK & 54.6 & 0.760 & 26 & $2 \%-33 \%$ & $1995 / 96$ \\
\hline Canada & 56.1 & 1.090 & 34 & $4 \%-38 \%$ & $1990 / 91$ \\
\hline Denmark & 56.1 & 1.100 & 32 & $0 \%-26 \%$ & $1998 / 99$ \\
\hline Latvia & 56.9 & 1.095 & 25 & $1 \%-14 \%$ & $2005 / 06$ \\
\hline Estonia & 59.4 & 1.120 & 34 & $1 \%-7 \%$ & No \\
\hline Sweden & 62.7 & 0.990 & 34 & $0 \%-21 \%$ & $2001 / 02$ \\
\hline Finland $(\alpha)$ & 64.3 & 1.240 & 44 & $2 \%-34 \%$ & 1995/96 \\
\hline
\end{tabular}




\begin{tabular}{|c|c|c|c|c|c|}
\hline \multirow[b]{2}{*}{ Country } & \multirow{2}{*}{$\begin{array}{l}\text { Lati- } \\
\text { tude }\end{array}$} & \multirow{2}{*}{$\begin{array}{l}\text { EWM ad- } \\
\text { justment }\end{array}$} & \multirow{2}{*}{$\begin{array}{r}\text { Data (n) } \\
\text { up to } \\
2013 / 14\end{array}$} & \multicolumn{2}{|c|}{ Vaccination } \\
\hline & & & & Range & $\begin{array}{r}10 \% \\
\text { achieved }\end{array}$ \\
\hline Iceland & 64.9 & 0.935 & 34 & $1 \%-28 \%$ & $1986 / 87$ \\
\hline Norway & 66.8 & 1.020 & 34 & $1 \%-16 \%$ & $1995 / 96$ \\
\hline
\end{tabular}

(!) Data for USA extended to 2019/20 due to doses data available from US CDC. $(\alpha)$ Low vaccination at the beginning of the time series enables extrapolation back in time using an assumed linear trend. 
Table S2. Summary of data relating to each country $(n=98)$ included in the proportion elderly vaccinated study.

\begin{tabular}{|c|c|c|c|c|c|c|}
\hline \multirow{2}{*}{ Country } & \multirow{2}{*}{$\begin{array}{c}\text { EWM } \\
\text { Adjustment }\end{array}$} & \multirow{2}{*}{$\begin{array}{l}\text { Median } \\
\text { EWM }\end{array}$} & \multirow{2}{*}{$\begin{array}{l}\text { Data } \\
(n=)\end{array}$} & \multicolumn{3}{|c|}{ Age $65+$ vaccinated (\%) } \\
\hline & & & & Minimum & Maximum & Median \\
\hline Albania & 0.44 & $31.2 \%$ & 13 & $0 \%$ & $14 \%$ & $6 \%$ \\
\hline Armenia & 0.47 & $24.6 \%$ & 15 & $0 \%$ & $2 \%$ & $0 \%$ \\
\hline Australia & 0.72 & $16.6 \%$ & 32 & $12 \%$ & $79 \%$ & $58 \%$ \\
\hline Austria & 0.87 & $13.8 \%$ & 33 & $0 \%$ & $49 \%$ & $21 \%$ \\
\hline Azerbaijan & 0.79 & $14.9 \%$ & 21 & $0 \%$ & $0 \%$ & $0 \%$ \\
\hline Bahamas & 0.99 & $12.1 \%$ & 22 & $0 \%$ & $27 \%$ & $0 \%$ \\
\hline Barbados & 0.87 & $13.8 \%$ & 6 & $0 \%$ & $40 \%$ & $8 \%$ \\
\hline Belarus & 1.38 & $9.4 \%$ & 18 & $5 \%$ & $76 \%$ & $23 \%$ \\
\hline Belgium & 0.72 & $15.4 \%$ & 33 & $15 \%$ & $65 \%$ & $57 \%$ \\
\hline Bermuda & 0.62 & $19.6 \%$ & 17 & $0 \%$ & $12 \%$ & $0 \%$ \\
\hline Bosnia and Herzegovina & 0.97 & $12.4 \%$ & 10 & $0 \%$ & $0 \%$ & $0 \%$ \\
\hline Bulgaria & 0.71 & $17.6 \%$ & 20 & $2 \%$ & $20 \%$ & $8 \%$ \\
\hline Canada & 1.03 & $11.6 \%$ & 33 & $25 \%$ & $71 \%$ & $60 \%$ \\
\hline Chile & 0.57 & $21.2 \%$ & 32 & $3 \%$ & $68 \%$ & $18 \%$ \\
\hline Costa Rica & 1.54 & $8.2 \%$ & 26 & $0 \%$ & $50 \%$ & $15 \%$ \\
\hline Croatia & 0.78 & $16.0 \%$ & 31 & $0 \%$ & $43 \%$ & $23 \%$ \\
\hline Cuba & 1.22 & $9.7 \%$ & 26 & $0 \%$ & $99 \%$ & $28 \%$ \\
\hline Cyprus & 0.52 & $22.0 \%$ & 18 & $23 \%$ & $49 \%$ & $33 \%$ \\
\hline Czechia & 1.08 & $11.4 \%$ & 28 & $0 \%$ & $24 \%$ & $17 \%$ \\
\hline Denmark & 1.08 & $11.1 \%$ & 33 & $4 \%$ & $52 \%$ & $20 \%$ \\
\hline Egypt & 0.90 & $13.4 \%$ & 25 & $0 \%$ & $1 \%$ & $0 \%$ \\
\hline El Salvador & 1.20 & $10.0 \%$ & 23 & $0 \%$ & $42 \%$ & $12 \%$ \\
\hline England & 0.68 & $17.6 \%$ & 33 & $12 \%$ & $75 \%$ & $71 \%$ \\
\hline Estonia & 1.10 & $10.9 \%$ & 32 & $0 \%$ & $20 \%$ & $2 \%$ \\
\hline Finland & 1.12 & $10.7 \%$ & 33 & $4 \%$ & $52 \%$ & $40 \%$ \\
\hline France & 0.87 & $13.7 \%$ & 33 & $39 \%$ & $67 \%$ & $52 \%$ \\
\hline Georgia & 0.63 & $18.9 \%$ & 16 & $0 \%$ & $0 \%$ & $0 \%$ \\
\hline Germany & 1.00 & $12.0 \%$ & 33 & $13 \%$ & $63 \%$ & $38 \%$ \\
\hline Greece & 1.04 & $11.0 \%$ & 20 & $20 \%$ & $59 \%$ & $49 \%$ \\
\hline Greenland & 0.66 & $18.1 \%$ & 28 & $0 \%$ & $0 \%$ & $0 \%$ \\
\hline Guadeloupe & 1.18 & $10.1 \%$ & 6 & $0 \%$ & $18 \%$ & $9 \%$ \\
\hline Guam & 0.79 & $15.3 \%$ & 11 & $0 \%$ & $0 \%$ & $0 \%$ \\
\hline Guatemala & 2.42 & $5.0 \%$ & 9 & $1 \%$ & $15 \%$ & $9 \%$ \\
\hline Hong Kong SAR & 0.67 & $20.2 \%$ & 33 & $0 \%$ & $44 \%$ & $5 \%$ \\
\hline Hungary & 1.03 & $11.7 \%$ & 32 & $13 \%$ & $39 \%$ & $27 \%$ \\
\hline Iceland & 1.01 & $11.5 \%$ & 31 & $35 \%$ & $49 \%$ & $43 \%$ \\
\hline Ireland & 0.75 & $15.8 \%$ & 20 & $38 \%$ & $70 \%$ & $59 \%$ \\
\hline Israel & 0.57 & $21.4 \%$ & 27 & $43 \%$ & $66 \%$ & $49 \%$ \\
\hline
\end{tabular}




\begin{tabular}{|c|c|c|c|c|c|c|}
\hline \multirow{2}{*}{ Country } & \multirow{2}{*}{$\begin{array}{c}\text { EWM } \\
\text { Adjustment }\end{array}$} & \multirow{2}{*}{$\begin{array}{l}\text { Median } \\
\text { EWM }\end{array}$} & \multirow{2}{*}{$\begin{array}{l}\text { Data } \\
(n=)\end{array}$} & \multicolumn{3}{|c|}{ Age $65+$ vaccinated (\%) } \\
\hline & & & & Minimum & Maximum & Median \\
\hline Italy & 0.75 & $16.0 \%$ & 29 & $40 \%$ & $68 \%$ & $52 \%$ \\
\hline Japan & 0.64 & $18.9 \%$ & 33 & $0 \%$ & $57 \%$ & $48 \%$ \\
\hline Kazakhstan & 1.54 & $7.6 \%$ & 18 & $1 \%$ & $15 \%$ & $3 \%$ \\
\hline Kosovo & 0.80 & $15.0 \%$ & 9 & $0 \%$ & $0 \%$ & $0 \%$ \\
\hline Kuwait & 0.75 & $17.0 \%$ & 28 & $0 \%$ & $23 \%$ & $4 \%$ \\
\hline Kyrgyzstan & 1.76 & $6.8 \%$ & 13 & $0 \%$ & $7 \%$ & $1 \%$ \\
\hline Latvia & 1.01 & $12.1 \%$ & 31 & $0 \%$ & $15 \%$ & $3 \%$ \\
\hline Lebanon & 0.63 & $18.9 \%$ & 20 & $5 \%$ & $35 \%$ & $15 \%$ \\
\hline Liechtenstein & 0.47 & $25.6 \%$ & 32 & $20 \%$ & $30 \%$ & $27 \%$ \\
\hline Lithuania & 0.95 & $12.7 \%$ & 26 & $0 \%$ & $25 \%$ & $9 \%$ \\
\hline Luxembourg & 0.93 & $13.0 \%$ & 30 & $15 \%$ & $54 \%$ & $40 \%$ \\
\hline Macao SAR & 0.57 & $21.0 \%$ & 31 & $9 \%$ & $36 \%$ & $25 \%$ \\
\hline Malaysia & 2.13 & $5.6 \%$ & 24 & $0 \%$ & $1 \%$ & $0 \%$ \\
\hline Maldives & 0.89 & $13.6 \%$ & 24 & $0 \%$ & $6 \%$ & $0 \%$ \\
\hline Malta & 0.37 & $34.0 \%$ & 30 & $20 \%$ & $57 \%$ & $46 \%$ \\
\hline Martinique & 1.43 & $9.0 \%$ & 11 & $0 \%$ & $6 \%$ & $0 \%$ \\
\hline Mauritius & 0.86 & $13.9 \%$ & 26 & $0 \%$ & $51 \%$ & $14 \%$ \\
\hline Mexico & 0.74 & $15.9 \%$ & 27 & $1 \%$ & $88 \%$ & $51 \%$ \\
\hline Mongolia & 1.16 & $10.4 \%$ & 15 & $0 \%$ & $15 \%$ & $0 \%$ \\
\hline Montenegro & 0.89 & $13.5 \%$ & 14 & $14 \%$ & $31 \%$ & $17 \%$ \\
\hline Netherlands & 0.89 & $13.4 \%$ & 32 & $25 \%$ & $84 \%$ & $70 \%$ \\
\hline New Caledonia & 0.83 & $14.6 \%$ & 23 & $7 \%$ & $35 \%$ & $21 \%$ \\
\hline New Zealand & 0.67 & $18.4 \%$ & 33 & $9 \%$ & $69 \%$ & $58 \%$ \\
\hline North Macedonia & 0.83 & $14.7 \%$ & 22 & $0 \%$ & $12 \%$ & $4 \%$ \\
\hline Northern Ireland & 0.71 & $17.0 \%$ & 31 & $12 \%$ & $78 \%$ & $72 \%$ \\
\hline Norway & 0.96 & $12.4 \%$ & 33 & $15 \%$ & $44 \%$ & $31 \%$ \\
\hline Philippines & 1.77 & $6.8 \%$ & 16 & $0 \%$ & $9 \%$ & $2 \%$ \\
\hline Poland & 1.09 & $11.7 \%$ & 33 & $0 \%$ & $32 \%$ & $8 \%$ \\
\hline Portugal & 0.44 & $27.4 \%$ & 33 & $0 \%$ & $65 \%$ & $42 \%$ \\
\hline Puerto Rico & 1.18 & $10.2 \%$ & 22 & $0 \%$ & $37 \%$ & $8 \%$ \\
\hline Qatar & 0.88 & $13.2 \%$ & 23 & $0 \%$ & $59 \%$ & $5 \%$ \\
\hline Republic of Moldova & 0.66 & $18.3 \%$ & 20 & $0 \%$ & $5 \%$ & $3 \%$ \\
\hline Reunion & 1.03 & $12.5 \%$ & 10 & $0 \%$ & $0 \%$ & $0 \%$ \\
\hline Romania & 0.71 & $17.3 \%$ & 32 & $0 \%$ & $29 \%$ & $15 \%$ \\
\hline Russian Federation & 1.79 & $6.7 \%$ & 23 & $1 \%$ & $69 \%$ & $14 \%$ \\
\hline Saint Lucia & 0.78 & $15.3 \%$ & 4 & $0 \%$ & $0 \%$ & $0 \%$ \\
\hline Saint Vincent \& Grenadines & 0.73 & $16.1 \%$ & 17 & $0 \%$ & $20 \%$ & $0 \%$ \\
\hline Scotland & 0.81 & $14.8 \%$ & 30 & $12 \%$ & $77 \%$ & $72 \%$ \\
\hline Serbia & 0.95 & $12.7 \%$ & 19 & $0 \%$ & $15 \%$ & $9 \%$ \\
\hline Singapore & 1.56 & $7.4 \%$ & 31 & $2 \%$ & $21 \%$ & $8 \%$ \\
\hline
\end{tabular}




\begin{tabular}{|c|c|c|c|c|c|c|}
\hline \multirow{2}{*}{ Country } & \multirow{2}{*}{$\begin{array}{c}\text { EWM } \\
\text { Adjustment }\end{array}$} & \multirow{2}{*}{$\begin{array}{c}\text { Median } \\
\text { EWM }\end{array}$} & \multirow{2}{*}{$\begin{array}{l}\text { Data } \\
(n=)\end{array}$} & \multicolumn{3}{|c|}{ Age $65+$ vaccinated (\%) } \\
\hline & & & & Minimum & Maximum & Median \\
\hline Slovakia & 1.32 & $9.1 \%$ & 29 & $0 \%$ & $38 \%$ & $14 \%$ \\
\hline Slovenia & 0.83 & $14.2 \%$ & 32 & $0 \%$ & $35 \%$ & $13 \%$ \\
\hline South Africa & 0.95 & $12.6 \%$ & 18 & $0 \%$ & $17 \%$ & $3 \%$ \\
\hline South Korea & 1.46 & $8.2 \%$ & 27 & $9 \%$ & $86 \%$ & $73 \%$ \\
\hline Spain & 0.60 & $20.0 \%$ & 33 & $37 \%$ & $70 \%$ & $58 \%$ \\
\hline Sri Lanka & 1.12 & $10.7 \%$ & 13 & $0 \%$ & $0 \%$ & $0 \%$ \\
\hline Suriname & 1.31 & $9.1 \%$ & 16 & $0 \%$ & $0 \%$ & $0 \%$ \\
\hline Sweden & 0.94 & $12.7 \%$ & 33 & $13 \%$ & $66 \%$ & $44 \%$ \\
\hline Switzerland & 0.82 & $14.6 \%$ & 32 & $14 \%$ & $61 \%$ & $36 \%$ \\
\hline Trinidad and Tobago & 1.44 & $9.6 \%$ & 17 & $0 \%$ & $25 \%$ & $2 \%$ \\
\hline Turkey & 0.82 & $14.6 \%$ & 21 & $1 \%$ & $13 \%$ & $6 \%$ \\
\hline Ukraine & 1.10 & $11.5 \%$ & 27 & $0 \%$ & $70 \%$ & $0 \%$ \\
\hline United Kingdom & 1.00 & $12.0 \%$ & 33 & $12 \%$ & $75 \%$ & $71 \%$ \\
\hline Uruguay & 0.42 & $30.5 \%$ & 18 & $0 \%$ & $70 \%$ & $0 \%$ \\
\hline US Virgin Islands & 0.86 & $15.0 \%$ & 7 & $0 \%$ & $16 \%$ & $2 \%$ \\
\hline USA & 1.00 & $12.0 \%$ & 33 & $36 \%$ & $71 \%$ & $65 \%$ \\
\hline Uzbekistan & 1.30 & $9.2 \%$ & 12 & $0 \%$ & $13 \%$ & $0 \%$ \\
\hline Venezuela & 1.59 & $8.0 \%$ & 13 & $0 \%$ & $50 \%$ & $15 \%$ \\
\hline Wales & 0.74 & $16.1 \%$ & 20 & $9 \%$ & $69 \%$ & $60 \%$ \\
\hline
\end{tabular}


Figure S1: US CDC estimated flu deaths (adjusted for growth in deaths over time) versus EWM

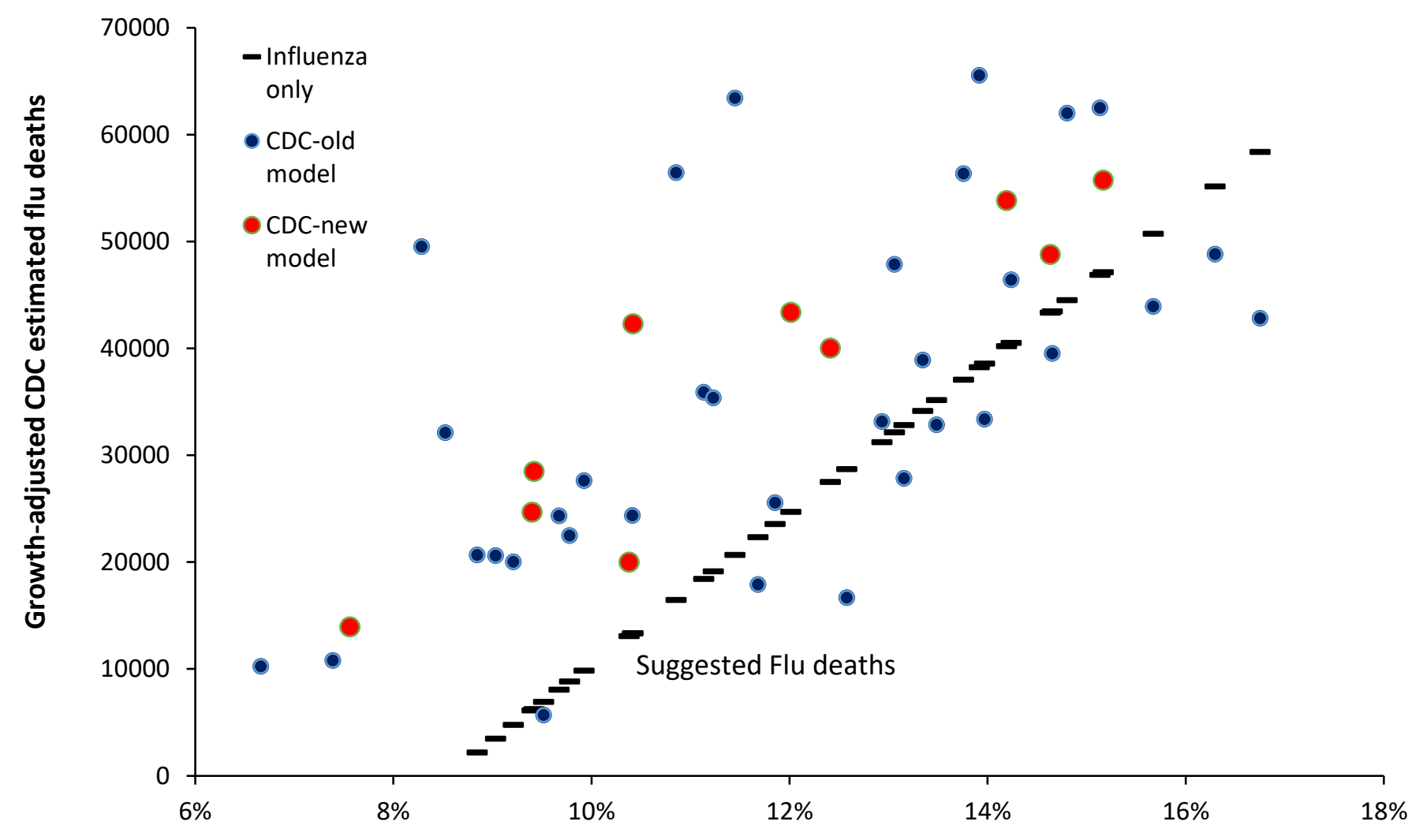

\section{Excess winter mortality (EWM)}

Footnote: CDC estimated flu deaths were first adjusted for the growth in total deaths over time. Data is from [77-81]. The underlying trend in total deaths was determined from a series of polynomial curve fits giving an adjustment factor for each year taking flu deaths to the 2020 equivalent. Over time the CDC has used two models to estimate flu deaths (old model covers 1976/77 to 2006/07, while the new model is from 2007/08 onward) of which the most recent model gives higher estimated flu deaths [77-81]. Data from the earlier model was adjusted up to the more recent model by plotting both sets of data against EWM and using the difference between the regression lines as the adjustment factor. The line for suggested flu deaths is in line with Figures 5 and A3. Note the far higher scatter in the CDC results, with an R-squared of only 0.4368. The R-squared for the old model is 0.448 while that for the new model is 0.8403 . This scatter arises because the CDC uses a limited sample of hospitals from which admissions and other surveillance data are used to estimate flu deaths. As a result, there are multiple sampling issues, hidden assumptions, and adjustment factor issues. While the new CDC model has a higher R-squared, the CDC models are less reliable than may be expected and lead to over-estimated influenza deaths.

On average the CDC model overestimates flu deaths by around 30\% and in the high years (mainly for the old model) gives flu deaths which are incompatible with excess winter deaths (EWD).

After adjusting all years for the growth in total deaths in the USA over the period 1957/58 to 2019/20 there was a median of 1.047 million winter deaths (interquartile range 1.027 - 1.063 million), a median excess winter deaths of 108,500 (IQR 89,800 - 130,700), and a median estimated winter influenza deaths of 30,000 (IQR 20,000 - 43,000). Estimated influenza deaths as a proportion of excess winter deaths had a median of $28 \%$ (IQR $20 \%-36 \%$ ). The proportion influenza deaths reached a maximum of $50 \%$ of excess winter deaths in the winter of $2001 / 02$, which was not a pandemic year. Hence within these ranges there is ample opportunity for the estimated influenza deaths to "steal" from otherwise unrelated reported cause of death in persons who would otherwise have died in that year.

For the USA, EWM reached a minimum in 2011/12 of 7.6\% and the US CDC noted that this winter set a record for the lowest and shortest peak in ILI [79]. Outpatient visits, inpatient admissions and deaths were at baseline levels, i.e, 2011/12 represents the lowest possible influenza year. Other than 3 high years between 1997/98 to 1999/00 (14.2\%, 15.7\%, 16.8\% EWM), EWM reached a maximum of $15.2 \%$ during the winter of 2014/15 and $14.2 \%$ in $2017 / 18$. Both later years saw high influenza outpatient visits, hospitalizations, and deaths [72,73]. Hence EWM is correctly detecting the severity of each influenza season. The CDC estimated 12,000 influenza deaths in 2011/12 and 52,000 in 2017/18 [79,81]. 
Figure S2. Trend in EWM for Denmark, Iceland, Singapore, and Sweden over the 60-year period 1960 to 2020

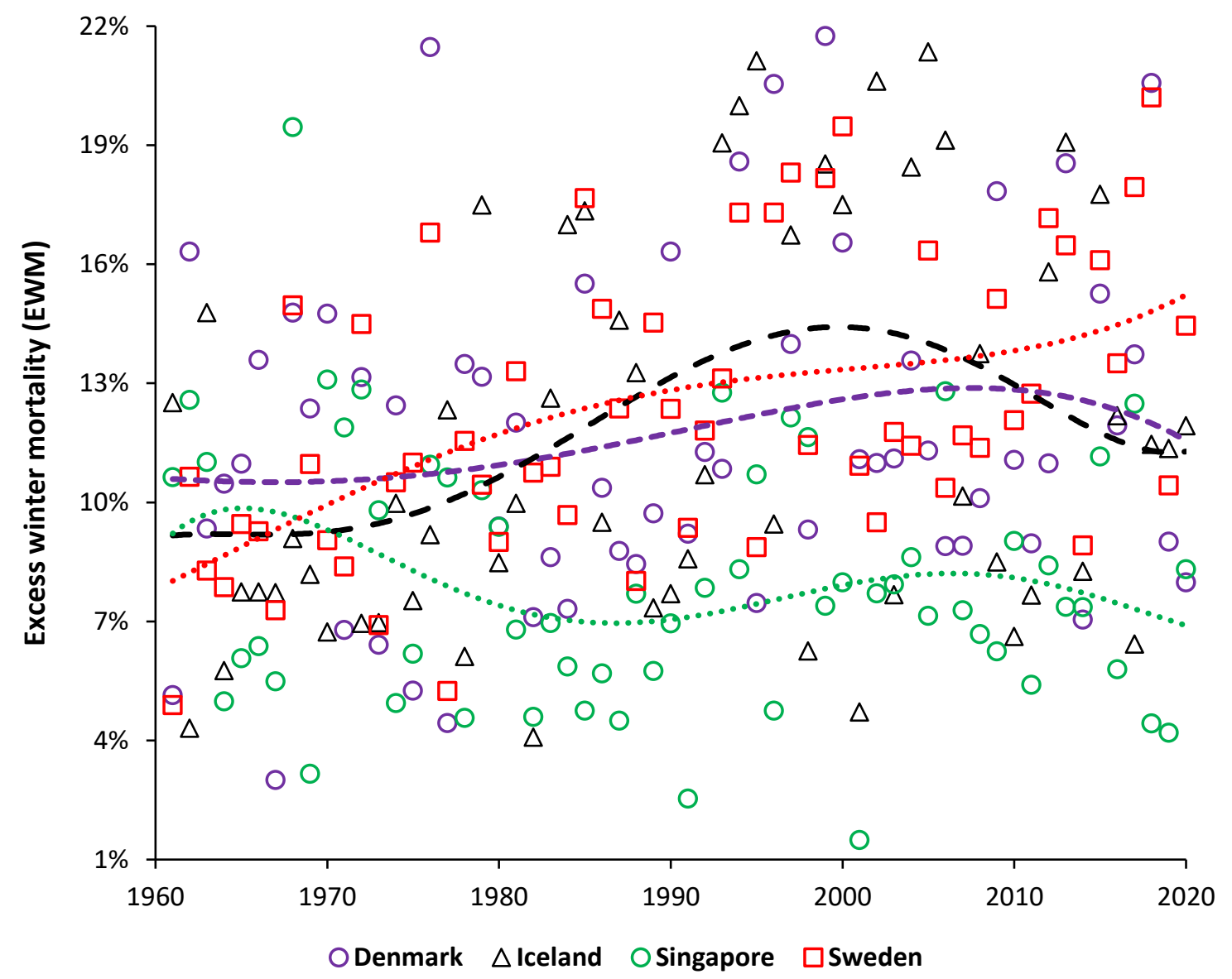

Footnote: The trend for each country is estimated using a $4^{\text {th }}$ or $5^{\text {th }}$ order polynomial. Singapore (closest to the equator) seems to have a slight downward trend while Sweden appears to have the highest trend upward. During the period 1992 to 2010 obesity among Singaporeans aged $60-69$ was static [132]. Singapore has traditionally been a low influenza vaccination country and vaccination of the elderly has only increased very recently. The trends are dominated by very high year-to-year volatility which is reflected in the high volatility in Figure 6. Since this study ran from 1980 onward it is considered that adjustment for the underlying trends relative to the USA would make only a small impact on the observed volatility in Figure 6 . The non-linear trends are consistent with the overall observation of this paper that long-term trends in EWM are regulated by very complex factors and their potential interactions. 